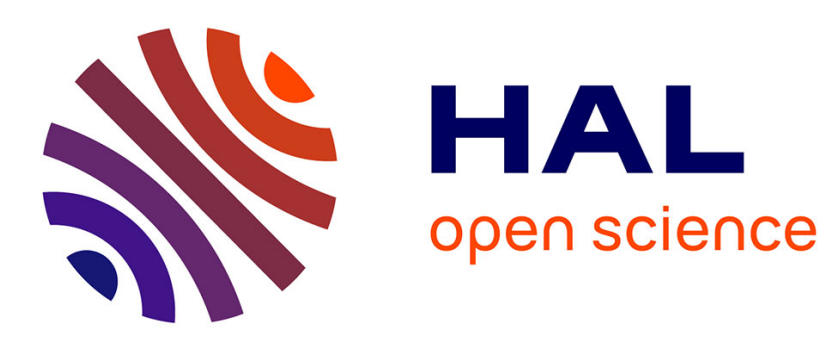

\title{
Investigation of 3D printing strategy on the mechanical performance of coextruded continuous carbon fiber reinforced PETG
}

\author{
Samir Kasmi, Geoffrey Ginoux, Samir Allaoui, Sébastien Alix
}

\section{To cite this version:}

Samir Kasmi, Geoffrey Ginoux, Samir Allaoui, Sébastien Alix. Investigation of 3D printing strategy on the mechanical performance of coextruded continuous carbon fiber reinforced PETG. Journal of Applied Polymer Science, 2021, 138 (37), pp.50955. 10.1002/app.50955 . hal-03222664

\section{HAL Id: hal-03222664 \\ https://hal.science/hal-03222664}

Submitted on 5 Sep 2021

HAL is a multi-disciplinary open access archive for the deposit and dissemination of scientific research documents, whether they are published or not. The documents may come from teaching and research institutions in France or abroad, or from public or private research centers.
L'archive ouverte pluridisciplinaire HAL, est destinée au dépôt et à la diffusion de documents scientifiques de niveau recherche, publiés ou non, émanant des établissements d'enseignement et de recherche français ou étrangers, des laboratoires publics ou privés. 


\title{
Investigation of 3D printing strategy on the mechanical performance of coextruded continuous carbon fiber reinforced PETG
}

\section{$\underline{\text { Samir Kasmi }}{ }^{1}$, Geoffrey Ginoux ${ }^{1}$, Samir Allaoui ${ }^{1}$, Sébastien Alix ${ }^{1}$}

${ }^{1}$ Université de Reims Champagne-Ardenne, ITheMM EA 7548, Campus Sup Ardenne, 08000 Charleville-Mézières, France.

\begin{abstract}
Fused filament fabrication (FFF) has been used to create prototypes and functional parts for various applications using plastic filaments. It has also been extended to the use of continuous fibers for reinforcing thermoplastic polymers. This study aims to optimize the deposition design of a coextruded Continuous Carbon Fiber (CCF) composite filament with a polyethylene terephthalate glycol-modified (PETG) filament. The characterisations on the raw materials revealed that the matrix polymer in CCF composite filament had similar physicochemical properties as PETG, and carbon fibers were homogeneously distributed in CCF filament. The effect of raster orientation and shells number on the mechanical properties of non-reinforced and coextruded CCF-reinforced PETG was investigated. The highest mechanical properties were obtained at a raster orientation of $0^{\circ}$ for both reinforced and non-reinforced materials. With the increase of raster orientation, Young's modulus and ultimate tensile strength decreased. The presence of shells improved the tensile strength of non-reinforced PETG. For composite samples printed with unreinforced shells, Young's modulus decreased due to decrease in fibers content, and elongation at break and ultimate tensile strength increased. Tomographic observations showed that the mechanical behavior of printed specimens depended on the anisotropy of porosity in printed specimens.
\end{abstract}

\section{Introduction}

Additive manufacturing (AM), popularly named 3D printing, creates a three-dimensional physical product directly from a digital design by adding material to the surface of a substrate layer-by-layer until the fabrication of the full shape is complete. AM technology offers an easyto-use process for fabricating solid parts with complex geometry that other conventional processes cannot accomplish. It has been used in numerous applications including automotive, biomedical, aerospace, and other fields ${ }^{1}$. In the last few years, it has been developed to add functionalities to printed parts ${ }^{2}$. 
There are different types of AM technology such as stereolithography for photopolymer liquid ${ }^{3}$, laminated object manufacturing for plastic lamination ${ }^{4}$, selective laser sintering for plastic powders ${ }^{5}$, and fused filament fabrication (FFF) for plastic filaments ${ }^{6}$. FFF process is the most common AM technology in several domains due to the low cost of FFF machines and the wide range of raw materials, typically thermoplastic materials in the filament form. The two most common thermoplastic materials used are: (i) polylactic acid (PLA), which is known for its low cost, dimensional accuracy, and printing ease, and (ii) acrylonitrile-butadiene-styrene copolymer (ABS), which is known for its durability and low cost. Other thermoplastic polymers are also used in FFF process, such as polycarbonate (PC) for its good mechanical performance and durability, and polyethylene terephthalate glycol-modified (PETG), which is easy-to-print with a good surface finish and high-water resistance. No matter the type of polymer, the mechanical properties of FFF printed parts are suboptimal and cannot be applied in applications which need products with high strength and mechanical performance. Numerous studies have focused extensively on improving the mechanical properties of FFF-printed samples by optimizing the printing parameters ${ }^{7}$. This solution has enhanced the mechanical properties of printed parts, but the improvement is still not significant for high performance applications. As a satisfactory solution to increase the mechanical properties of FFF-printed products, and to functionalize the printed parts, reinforced materials have been developed for FFF technology by adding: layered silicate ${ }^{8}$, metal ${ }^{9,10}$, ferroelectric barium titanate $\left(\mathrm{BaTiO}_{3}\right)^{11}$, silicon carbide $(\mathrm{SiC})^{12}$, natural fillers in the form of short natural fibers ${ }^{13}$, short glass fiber ${ }^{14}$, short basalt fiber ${ }^{15}$, and short carbon fiber ${ }^{16}$. Using short fibers achieves low cost, higher strength and stiffness, low weight, and strong dimensional stability by preventing shrinkage during the cooling step $^{17}$, which is a major issue hardly eliminated by the sole parametric optimization ${ }^{18}$. However, the mechanical performance remains low compared to what is needed for structural parts, leading to the use of continuous fibers as a solution to increase the mechanical performance of the reinforced polymers ${ }^{19}$.

Various continuous fibers have been used to reinforce the mechanical properties of thermoplastic polymers including Kevlar ${ }^{20}$, carbon $^{21}$, glass ${ }^{22}$, and bamboo ${ }^{23}$, but it appears that continuous carbon fibers give the best mechanical improvements. FFF parameters influenced the mechanical properties of continuous fibers-reinforced thermoplastic polymers ${ }^{24}$. For the raster orientation, the highest mechanical properties were obtained at $0^{\circ}$ with all layers printed parallel to the loading direction, and the lowest values were obtained at $90^{\circ}$ with all layers printed normal to the loading direction ${ }^{25}$. The mechanical performance of printed reinforced samples using continuous fibers was similar to the performance of reinforced samples prepared 
using an injection process ${ }^{26}$. As compared with other conventional processes, anisotropic properties in printed parts were found due to the internal porosity between deposited filaments ${ }^{27}$.

The above literature review shows that the mechanical performance of the polymer matrix highly increases in the presence of continuous fibers. This improvement depends on the printing parameters, the type of fiber and the fiber/matrix adhesion. In this study, PETG matrix, which has not been studied in AM with continuous fibers ${ }^{28}$, was deposited simultaneously with carbon fibers in coextrusion process for mechanical optimization regarding process, design, and materials formulation. The coextrusion process offers a wide range of configurations, especially when coupled with a multi-nozzle/multi-component system, for printed composite parts as compared with other standard FFF processes presented in literature. The strategy of continuous carbon fiber orientation deposition on the mechanical performance of PETG/carbon composite using FFF was investigated. Materials performance was assessed using mechanical and thermal characterizations, coupled with tomographic observations. The impact of unreinforced shells was evaluated to limit the early propagation of fracture in printed samples, possible thanks to the multi-nozzle system for multi-component functionalization. Non-reinforced PETG and Continuous Carbon Fiber (CCF)-reinforced PETG samples were printed at different raster orientations. Non-reinforced PETG and CCF-reinforced PETG samples will be mentioned, respectively, with PETG and PETG-CCF samples. The compatibility between PETG and the matrix polymer in CCF composite filament was explored by comparing their physicochemical properties. The influence of raster orientation and shells presence on the tensile properties of PETG and PETG-CCF specimens was also studied. Tomographic and optical microscopy observations were conducted, respectively, to determine the internal porosity and to assess the failure mode as a function of raster orientation.

\section{Materials and methods}

\subsection{Materials}

PETG matrix filament under PolyMax ${ }^{\mathrm{TM}}$ brand from Polymaker (France) was supplied by Imprimante3DFrance (France). This filament, with a diameter of $1.75 \mathrm{~mm}$, was used for the preparation of PETG specimens at different raster orientations. Some of its properties, according to the supplier, are as follows: Young's modulus of $1523 \pm 50 \mathrm{MPa}$, tensile strength of $31.7 \pm 0.1 \mathrm{MPa}$, and a glass transition temperature of $79^{\circ} \mathrm{C}$. Composite filament under the brand Anisoprint (Russia) was supplied by Imprimante3DFrance (France). This coextruded continuous carbon fiber composite filament was composed of continuous carbon fibers (1500 
fibers in a bundle) and a polymer matrix. Table 1 lists some of its properties presented in the technical sheet. CCF was printed with PETG to prepare PETG-CCF specimens at different raster orientations.

\begin{tabular}{|l|c|}
\hline \multicolumn{1}{|c|}{ Properties } & Value \\
\hline Effective diameter $(\mathrm{mm})$ & $0.35 \pm 0.01$ \\
\hline Linear density (Tex) & $145 \pm 10$ \\
\hline Ultimate load $(\mathrm{N})$ & $212 \pm 10$ \\
\hline Young's modulus $(\mathrm{GPa})$ & $149 \pm 5$ \\
\hline Max printing temperature $\left({ }^{\circ} \mathrm{C}\right)$ & 270 \\
\hline
\end{tabular}

Table 1: CCF composite filament properties provided by Anisoprint.

\subsubsection{D printer}

All samples were prepared using a Composer A4 3D printer from Anisoprint (Russia). The printer head was equipped with two nozzles, as shown in Figure 1.a: a standard nozzle (1) for thermoplastic filaments and a coextrusion nozzle (2), with two inputs, mixing PETG filament and CCF composite filament simultaneously. The schematic representation of the coextrusion nozzle is presented in Figure 1.b. The slicing software Aura (Anisoprint, Russia) enabled the modification of different printing parameters such as nozzle temperature, bed temperature, layer thickness, infill orientation, fiber type, printing speed, etc. The isotropic model was chosen for the fiber fill type, meaning that all fibers were aligned in the same direction as the chosen raster orientation from $0^{\circ}$ to $90^{\circ}$ compared to the tensile test direction.

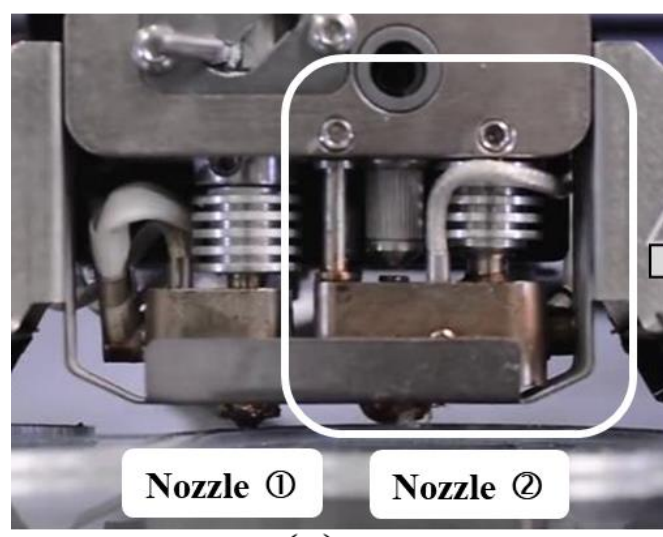

(a)

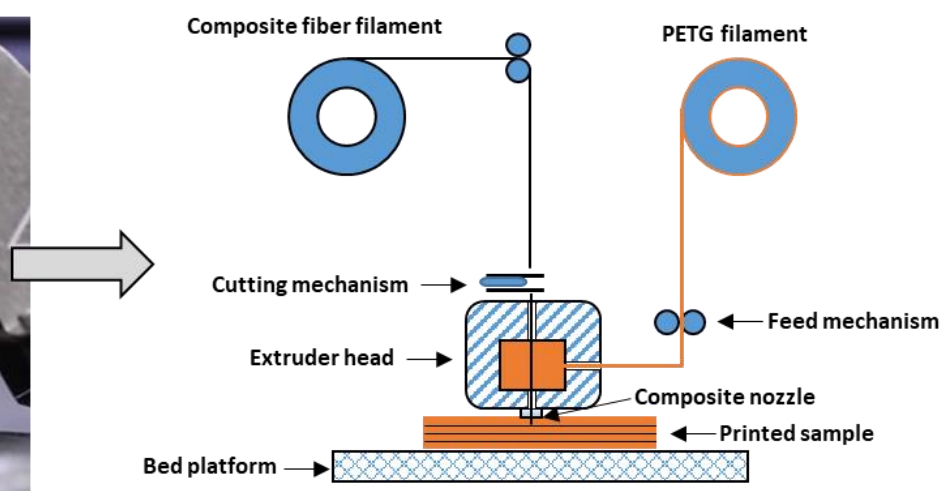

(b)

Figure 1: (a) Photography of the printing head of Anisoprint 3D printer and (b) schematic representation of the coextrusion nozzle. 


\subsection{Preparation of specimens}

Tensile test specimens were printed according to ASTM D638 type I with a thickness of 3.2 mm. Except for raster orientation, all other printing conditions of PETG and PETG-CCF samples were kept constant. Table 2 presents the printing settings of tensile test specimens. Two groups of specimens were printed: the first group concerned PETG samples and the second one for composite samples based PETG-CCF. The specimens of each group were printed without shells and with two shells of PETG. The shell is the wall of printed parts (represented in black in Figure 2). Six specimens of each group were printed at the same conditions for each following configuration: unidirectional layups including $0^{\circ}$ (parallel to the loading direction), $30^{\circ}, 45^{\circ}, 70^{\circ}, 90^{\circ}$ (normal to the loading direction), and alternate layups including $0^{\circ} / 90^{\circ}$, and $45^{\circ}-45^{\circ}$ (Figure 2).

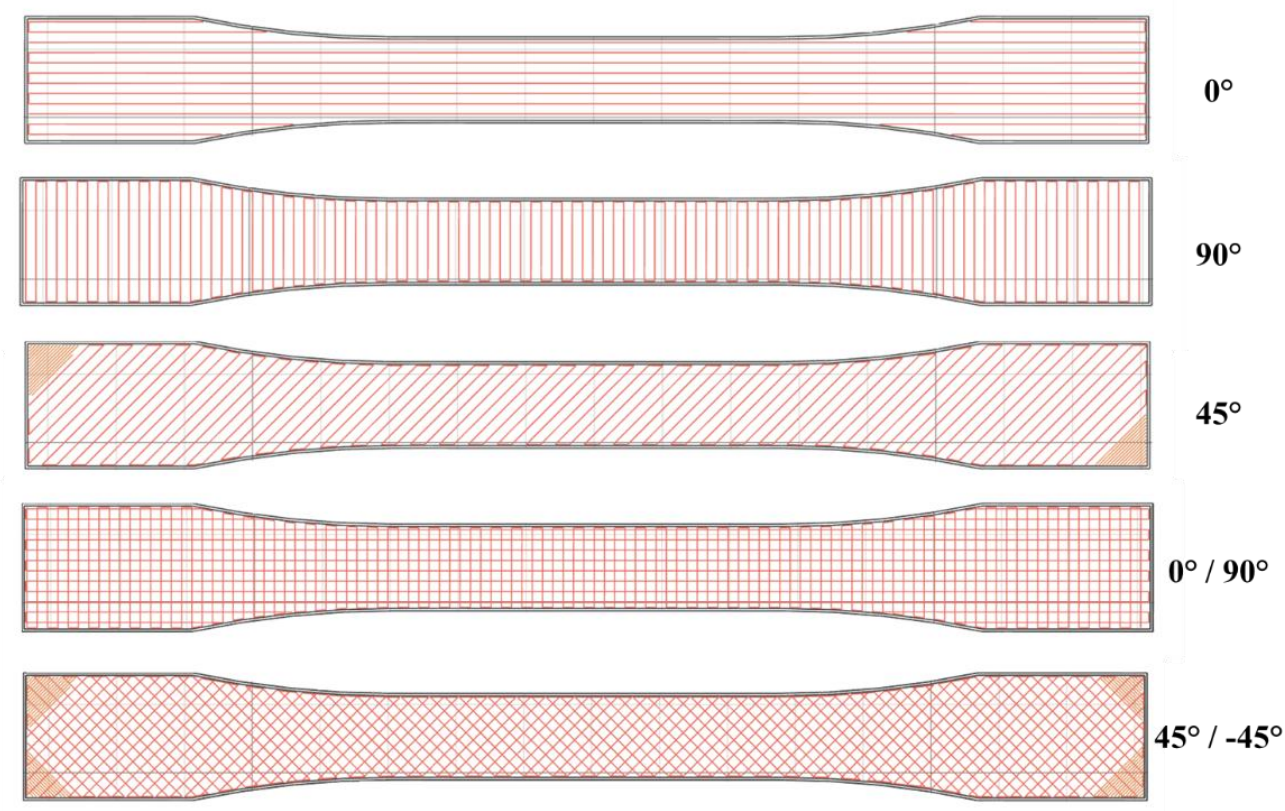

Figure 2: Schematic representation of some configurations printed with 2 shells of PETG: $0^{\circ}, 90^{\circ}, 4^{\circ}, 0^{\circ} / 90^{\circ}$, and $45^{\circ} /-45^{\circ}$ compared to the loading direction (shells in black and internal filling in red).

\begin{tabular}{|l|c|}
\hline \multicolumn{1}{|c|}{ Parameters } & Value \\
\hline Nozzle temperature $\left({ }^{\circ} \mathrm{C}\right)$ & 230 \\
\hline Bed temperature $\left({ }^{\circ} \mathrm{C}\right)$ & 60 \\
\hline Layer thickness $(\mathrm{mm})$ & 0.2 \\
\hline Printing speed $(\mathrm{mm} / \mathrm{s})$ & 50 \\
\hline Infill percentage $(\%)$ & 100 \\
\hline Raster orientation & $0^{\circ}, 30^{\circ}, 45^{\circ}, 70^{\circ}, 90^{\circ}, 0^{\circ} / 90^{\circ}$, and $45^{\circ} / 45^{\circ}$ \\
\hline
\end{tabular}

Table 2: List of 3D printing parameters applied to print tensile test specimens. 


\subsection{Characterization}

Various characterization methods were performed on the raw materials: firstly, to evaluate the similarity between the physicochemical properties of PETG filament and the matrix polymer in $\mathrm{CCF}$ composite filament, and secondly, to evaluate the effect of printing parameters on the mechanical properties of printed specimens. The compatibility between PETG and matrix polymer in CCF filament was evaluated using differential scanning calorimetry (DSC), thermogravimetric analysis (TGA) and Fourier transform infrared spectroscopy (FTIR). DSC and TGA were performed, respectively, to determine (i) glass transition temperature, melting temperature, and crystallization temperature, and (ii) thermal degradation behavior of PETG filament and matrix polymer in CCF composite filament. FTIR analysis was performed to identify the main chemical groups in common between each raw material. To evaluate the consistency of the used 3D printer machine, mass measurements of printed samples before tensile testing were performed to compare the real mass with the mass estimation given by the slicer software Aura. A first approach of the effect of raster orientation on the porosity in printed samples was provided by this mean. X-ray computed tomography instruments were used to characterize the fiber distribution in CCF composite filament, to measure the internal porosity, and to determine the relationship between $3 \mathrm{D}$ printing process and porosity distribution. Tensile tests were performed to mechanically characterize the CCF composite filament and to quantify the effects of raster orientation and of shell presence on the mechanical properties of PETG and PETG-CCF specimens printed at different configurations. After tensile test experiments, microstructural observations were performed to qualify the fracture propagation in printed specimens during tensile test.

DSC analysis was conducted on around $5 \mathrm{mg}$ of material, placed in hermetic aluminum pans, using DSC Q20 from TA Instruments (USA). Analysis was performed in a nitrogen atmosphere $\left(50 \mathrm{~mL} / \mathrm{min}\right.$ ) with two thermal cycles at a heating and a cooling rate of $10{ }^{\circ} \mathrm{C} / \mathrm{min}$ from $-50{ }^{\circ} \mathrm{C}$ to $300{ }^{\circ} \mathrm{C}$.

TGA was performed using TG 209 F3 Tarsus from Netzsch (Germany). Samples of around 5 mg were placed in open silica pans and then tested in a temperature range from $30{ }^{\circ} \mathrm{C}$ to 800 ${ }^{\circ} \mathrm{C}$ with a heating rate of $10{ }^{\circ} \mathrm{C} / \mathrm{min}$. The nitrogen flow rate was set at $20 \mathrm{~mL} / \mathrm{min}$.

FTIR spectroscopy was performed on a Spectrum II infrared spectrometer from PerkinElmer (USA) controlled by Spectrum SpecWin Pro software in a transmission range between $500 \mathrm{~cm}^{-}$ ${ }^{1}$ and $4000 \mathrm{~cm}^{-1}$ with a resolution of $4 \mathrm{~cm}^{-1}$. 
NanoTomograph (nCT) EasyTomXL 150/160 (RX-solutions, France) was used for morphological analysis. The scanning step used a X-ray source with a voxel size of around 1 $\mu \mathrm{m}$, a voltage of $100 \mathrm{kV}$, and a current of $200 \mu \mathrm{A}$. MicroTomograph $(\mu \mathrm{CT})$ DeskTom $150(\mathrm{RX}-$ solutions, France) was used for structural analysis. The scanning step used a X-ray source with a voxel size of $70 \mu \mathrm{m}$, a voltage of $60 \mathrm{KV}$, and a current of $500 \mu \mathrm{A}$. The reconstruction of 2D images into 3D volume was carried out with X-Act software (RX-solutions, France) for both tomographs. The volume and surface analyses were determined with VG Studio Max 3.0 software (RX-solutions, France).

Optical micrography was carried out a stereo microscope Nikon SMZ-2T (Japan) coupled with an imaging source camera with a resolution of $2.048 \times 1.536$ pixels and connected to an acquisition software named Archimed (Microvision Instruments, France).

Tensile tests were conducted, at ambient temperature, using an 810 universal testing machine (USA). An MTS634-12F-24 (USA) extensometer was attached continuously to record the sample strain during the tensile test. The crosshead speed was set at $5 \mathrm{~mm} / \mathrm{min}$. The value of each mechanical property, including Young's modulus, ultimate tensile strength, and elongation at break, is the average of five tensile test measurements.

Sample mass was determined using Analytical Balance Mettler Toledo (AE 240, MettlerToledo, USA) with a precision of $0.03 \mathrm{mg}$.

\section{Results and discussion}

\subsection{Physicochemical characterizations of raw materials}

The compatibility between PETG and matrix polymer in CCF composite filament was evaluated by comparing their physicochemical properties. DSC thermograms of PETG and CCF composite filaments during the second thermal cycle are presented in Figure 3. In DSC thermogram of PETG, there was a glass transition temperature but no melting peak or crystallization peak was detected. PETG filament was $100 \%$ amorphous with a glass transition temperature of around $78{ }^{\circ} \mathrm{C}$ which corresponds to the glass transition temperature mentioned in the technical sheet. The DSC thermogram of CCF composite filament had the same trend as the PETG thermogram. Only a glass transition temperature of around $79{ }^{\circ} \mathrm{C}$ was present. These two raw materials had similar glass transition temperature and they were both in the amorphous phase. 


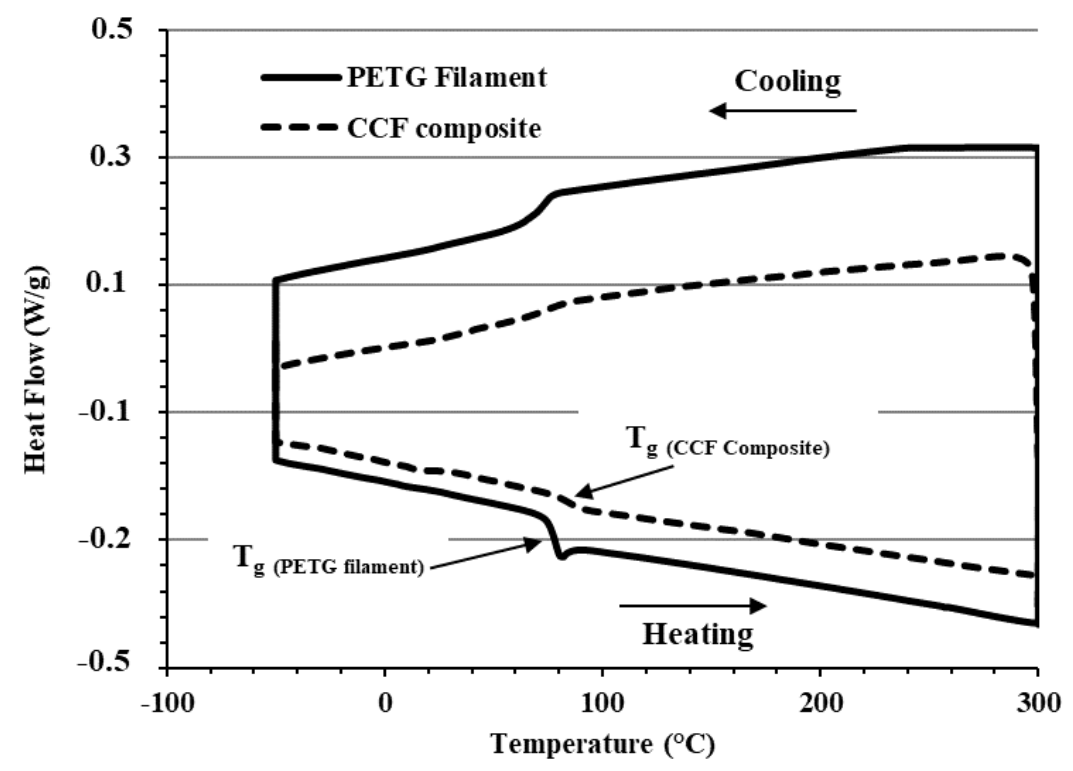

Figure 3: DSC thermograms of PETG and CCF composite filaments during the second thermal cycle under nitrogen atmosphere with a heating (and a cooling) rate of 10 ${ }^{\circ} \mathrm{C} / \mathrm{min}$ from $-50{ }^{\circ} \mathrm{C}$ to $300{ }^{\circ} \mathrm{C}$.

TGA experiments followed the thermal stability of PETG and CCF composite filaments. PETG and CCF composite filaments had a thermal degradation in a single step (Figure 4). For PETG filament, the thermal degradation started at $358{ }^{\circ} \mathrm{C}$, and a residue of $7 \%$ wt was still present at the end of the experiment. In contrast, the thermal degradation of CCF composite filament started at $353{ }^{\circ} \mathrm{C}$, slightly earlier than PETG but they had the same final degradation temperature of around $444^{\circ} \mathrm{C}$. The thermogram of CCF composite filament reached a consistent value at a mass loss of around $25 \%$. The observed thermal degradation step corresponded to the degradation of polymer matrix in the composite filament. The residue corresponded to the fibers content (around 75\%wt). In the initial CCF composite filament composition given by the supplier, the matrix polymer represented an initial mass percentage of $30 \%$ wt. However, only a mass loss of $25 \%$ wt was determined from TGA measurements. So, some interactions were present between CCF and matrix polymer with the formation of some carbonaceous residue in the pan. In addition, the matrix might have had residue mass (especially under nitrogen atmosphere). Similar observations were found on another type of carbon fiber ${ }^{29}$. 


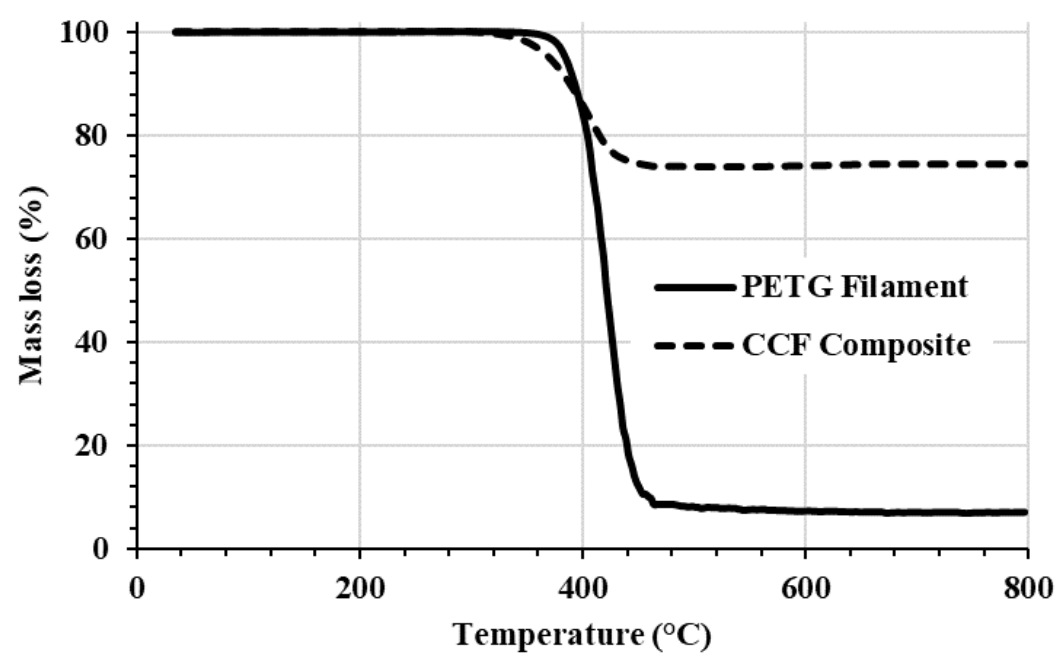

\section{Figure 4: TGA thermograms of PETG filament and CCF composite filament under nitrogen atmosphere at $10{ }^{\circ} \mathrm{C} / \mathrm{min}$ from $30{ }^{\circ} \mathrm{C}$ to $800{ }^{\circ} \mathrm{C}$.}

FTIR analyses identified the distribution of chemical groups present on the surface of each sample and determined the identical functional groups shared between PETG and CCF composite filaments. Every spectrum in Figure 5 represents the accumulation of eight scans with a resolution of $4 \mathrm{~cm}^{-1}$. Based on the literature ${ }^{30}$, some peaks present in PETG spectra at $2922 \mathrm{~cm}^{-1}$ refer to $\mathrm{C}-\mathrm{H}$ bends. The wide peak identified at $1718 \mathrm{~cm}^{-1}$ corresponds to the $\mathrm{C}=\mathrm{O}$ stretch of the ester group of PETG. The peak appearing at $1408 \mathrm{~cm}^{-1}$ corresponds to C-H bends. $\mathrm{C}-\mathrm{O}$ bends appeared at $1239 \mathrm{~cm}^{-1}$. The peak at $1089 \mathrm{~cm}^{-1}$ is attributable to the symmetrical C$\mathrm{O}$ bend, and the peak at $1010 \mathrm{~cm}^{-1}$ represents the $\mathrm{C}-\mathrm{H}$ bend. The peak at $876 \mathrm{~cm}^{-1}$ refers to the $\mathrm{C}-\mathrm{H}$ bends. For CCF composite filament ${ }^{31}$, the most important peak was present at $1729 \mathrm{~cm}^{-1}$ corresponding to the $\mathrm{C}=\mathrm{O}$ bend of $\mathrm{CCF}$ composite filament, identical to the same function present in PETG spectra. In addition, the C-H bends were present at $2925 \mathrm{~cm}^{-1}$ and $822 \mathrm{~cm}^{-1}$. The $\mathrm{C}-\mathrm{C}$ bend was appeared at $1505 \mathrm{~cm}^{-1}$. In conclusion, PETG and CCF spectras had several common peaks especially the peak corresponding to the carbonyl function. As a result, PETG and CCF filaments might have a chemical compatibility which can improve the quality of printed filaments during $3 \mathrm{D}$ process. 


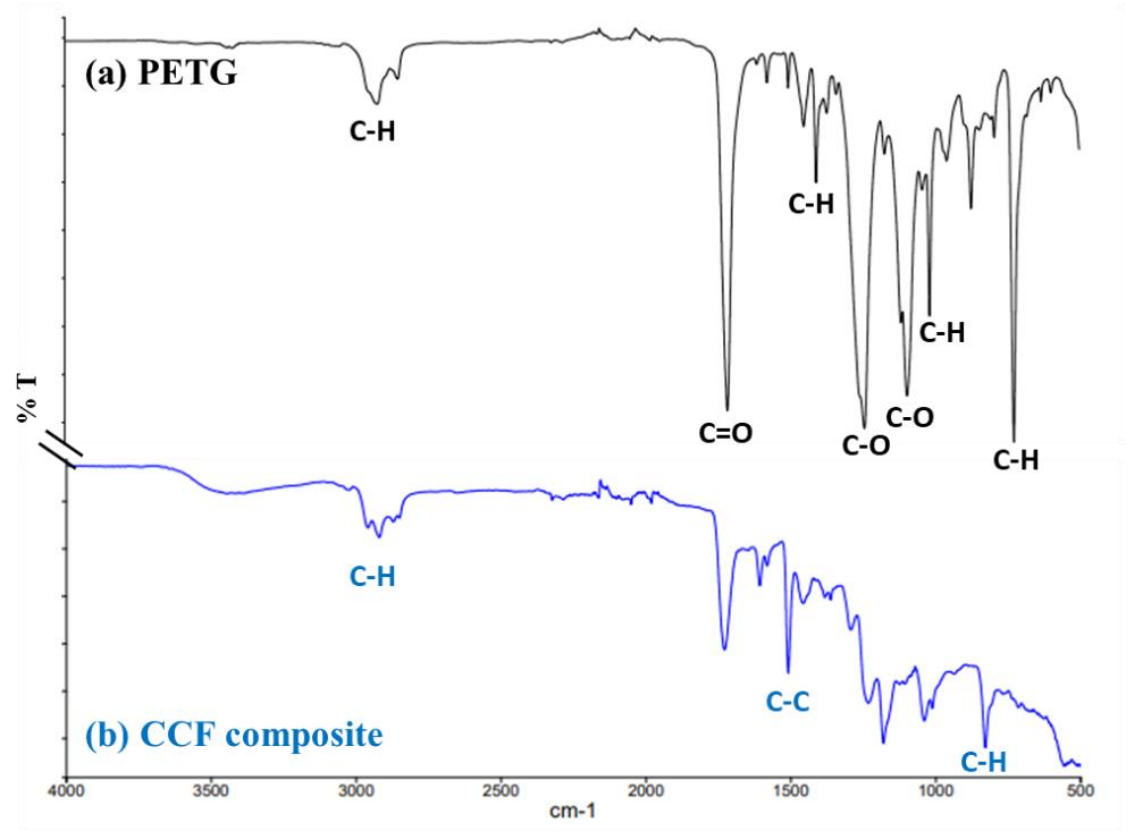

\section{Figure 5: FTIR Spectra of (a) PETG filament and (b) CCF composite filament in a transmission range between $500 \mathrm{~cm}^{-1}$ and $4000 \mathrm{~cm}^{-1}$.}

According to the physicochemical characterizations, PETG and CCF composite filaments had the same final degradation temperature and glass transition temperature. They also shared some chemical groups. These results demonstrate that CCF composite filament was composed of continuous carbon fiber impregnated in a matrix polymer that had similar physicochemical properties to those of PETG filament. PETG and CCF composite filaments are used in this study to print composite specimens. They have a good compatibility which can provide a good adhesion in the coextruded filaments during 3D printing process.

\subsection{Morphological and mechanical characterizations of CCF composite filament}

nCT analysis evaluated the quality of the fibers distribution, void presence, and fibers longitudinal alignment. Figure 6 showed a cross-section and longitudinal nanotomography performed using $\mathrm{nCT}$ analysis of unidirectional CCF composite filament. The figure shows that the fibers were impregnated with a homogeneous distribution in the matrix polymer. They were longitudinally aligned with no void content in the structure at $1 \mu \mathrm{m}$ of resolution. CCF filament also had an elliptical shape with a calculated equivalent diameter of $0.34 \mathrm{~mm}$ (Figure 6), which is similar to the effective diameter mentioned in the technical sheet. The calculated diameter of one carbon fiber was around $7 \mu \mathrm{m}$. With good distribution of fibers and lower porosity in CCF composite filament, the printed parts in this study have a good filling quality, which is required for high mechanical performance. 

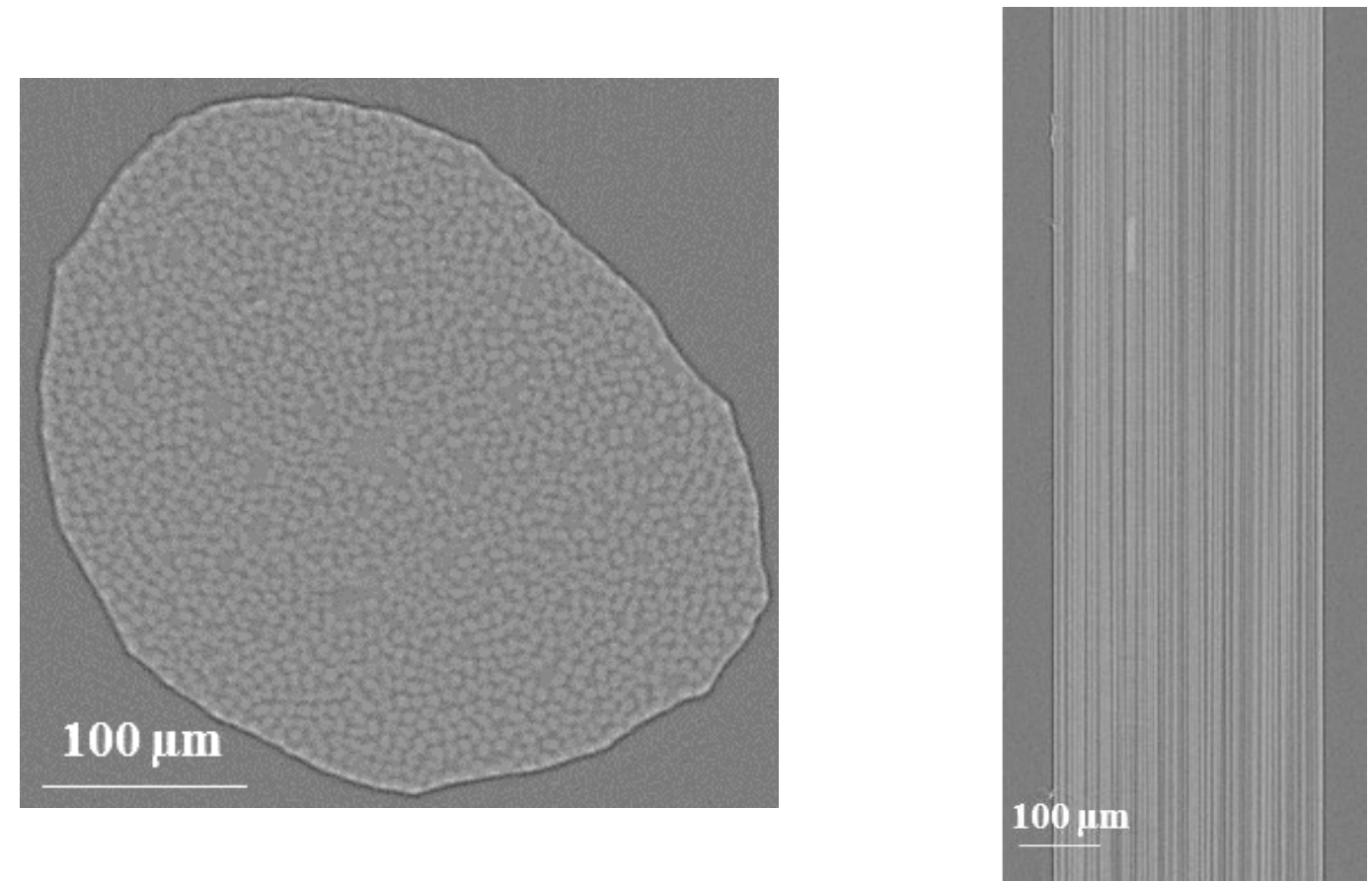

\section{Figure 6: Cross-section (left) and longitudinal (right) nanotomographic observations of CCF composite filament with $1 \mu \mathrm{m}$ voxel.}

Tensile test experiments determined the tensile properties of CCF composite filament. The experiments focused on a single CCF composite filament and tested four samples oriented in the loading direction. Aluminium plates were glued to each specimen's side using a twocomponent epoxy adhesive. Figure 7 presents the strength-strain curve of CCF composite filament. A quasi-linear curve was obtained with the absence of non-linearity in the beginning and at the end of the curve as a sign of the predominance of fibers behavior. The average ultimate tensile strength was $2260 \pm 225 \mathrm{MPa}$ and corresponded to an ultimate load of $220 \pm$ $20 \mathrm{~N}$. This result is similar to the ultimate load mentioned in the technical sheet. The determined elastic modulus was around $123 \pm 5 \mathrm{GPa}$, which is slightly lower than the modulus in the technical sheet (149 $\pm 5 \mathrm{GPa}$ ). This difference might be due to the presence of broken fibers in the filament before the experiment. Alternately, some fibers might not have been perfectly aligned in the longitudinal direction. The elongation at break was around $2.2 \pm 0.7 \%$. When the stress increased, a slight drop of the force at a strain of $0.7 \%$ and $1.8 \%$ was observed and then followed by an increase. These drops might be attributed to the rupture of some fibers that reached their ultimate's strain as observed in previous studies ${ }^{32}$. 

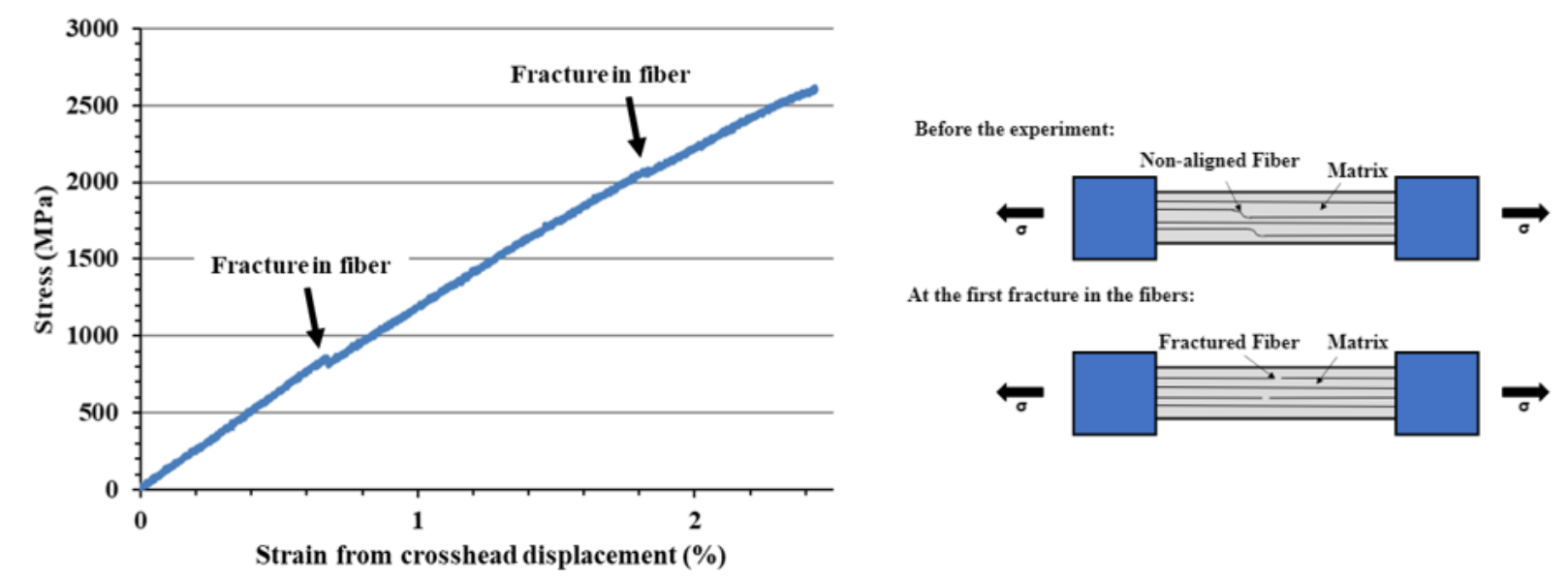

Figure 7: Stress-strain curve of single CCF composite filament under a crosshead speed of $5 \mathrm{~mm} / \mathrm{min}$.

\subsection{Process-properties relationship}

Once PETG and CCF composite filaments, as raw materials, were characterised, they were used to prepare tensile test specimens using 3D printing coextrusion process. Assessing the accuracy of Anisoprint 3D printer involved measuring the weight of the specimens and comparing this to the theorical weight provided by the slicer Aura. These measurements were performed on PETG and PETG-CCF samples printed with two shells of PETG at different orientations (Table 3). The mass deviation can be used as an indicator of the porosity presence in the printed specimens.

\begin{tabular}{|c|c|c|c|}
\hline Specimens & Average mass $(\mathbf{g})$ & $\begin{array}{c}\text { Mass estimation } \\
\text { from Aura (g) }\end{array}$ & Error (\%) \\
\hline PETG samples & $9.50 \pm 0.06$ & 10.1 & -5.9 \\
$0^{\circ}$ & $9.41 \pm 0.04$ & 10.1 & -6.9 \\
$30^{\circ}$ & $9.48 \pm 0.04$ & 10.2 & -7.0 \\
$45^{\circ}$ & $9.41 \pm 0.02$ & 10.1 & -6.8 \\
$70^{\circ}$ & $9.56 \pm 0.03$ & 10.2 & -6.3 \\
$90^{\circ}$ & $9.55 \pm 0.06$ & 10.1 & -5.4 \\
$0^{\circ} / 90^{\circ}$ & $9.67 \pm 0.02$ & 10.2 & -5.1 \\
$45^{\circ} /-45^{\circ}$ & & & -9.0 \\
$0^{\circ}$ & $9.94 \pm 0.45$ & 10.8 & -9.4 \\
$45^{\circ}$ & $10.36 \pm 0.92$ & 11.3 & -6.6 \\
$90^{\circ}$ & $10.52 \pm 0.61$ & 11.1 & -4.1 \\
$0^{\circ} / 90^{\circ}$ & $10.51 \pm 0.45$ & 11.0 & -3.7 \\
$45^{\circ} /-45^{\circ}$ & $10.94 \pm 0.16$ & 11.3 & \\
\hline
\end{tabular}


Table 3: Mass measurements of tensile test specimens based PETG and PETG-CCF printed with two shells of PETG for different raster orientations with corresponding error from predicted mass.

The mass estimation from Aura software was given in gram units with a precision of $0.1 \mathrm{~g}$. It was nearly consistent for PETG and PETG-CCF samples at around $10.1 \mathrm{~g}$ and $11.1 \mathrm{~g}$, respectively, at all raster orientations. As compared with the estimated mass, the measured mass of PETG samples deviated with an error between $-7 \%$ and $-5.1 \%$ for all specimens. The highest and lowest values were obtained, respectively, at a raster orientation of $45^{\circ}$ and $45^{\circ} /-45^{\circ}$. However, for PETG-CCF samples, the error was between $-9 \%$ and $-3.7 \%$. The highest error of $-9.4 \%$ was obtained at a raster orientation of $0^{\circ}$ and $45^{\circ}$. The lowest error of $-3 \%$ was obtained at a raster orientation of $45^{\circ} /-45^{\circ}$. These results indicate that the real mass of the printed samples was lower than the estimated mass, and this difference is higher for specimens printed unidirectionally as compared with those printed with alternate layups. For the same raster orientation with unidirectional layups, the mass deviation was higher for PETG-CCF samples compared to PETG samples. This difference can be attributed to the presence of porosity between printed composite filaments. Microtomography observations were performed to determine the internal porosity and evaluate the correlation between the porosity and the raster orientation of the specimens.

The scanned area during $\mu \mathrm{CT}$ analysis focused on the useful area of the tensile test specimens and the generated $3 \mathrm{D}$ volume is presented in Figure 8 . The segmentation was reached by applying a manual surface determination. The sample volume was created to limit the open pores and to define a zone of interest. This then resulted in a quantitative analysis of the porosity between deposited filaments printed in different configurations.

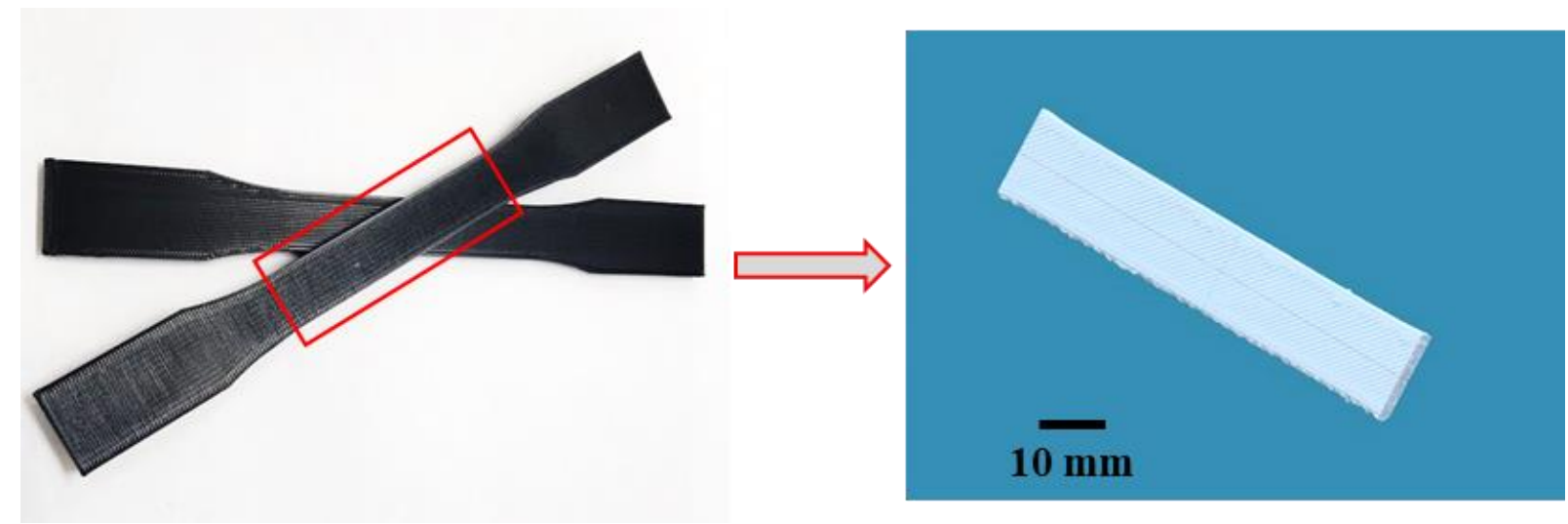

Figure 8: Generated 3D volume (right) of the scanned area (left, in red rectangle) in $\mu C T$ analysis of PETG and PETG-CCF specimens with a resolution of $70 \mu \mathrm{m}$. 
Table 4 presents an example of porosity measurements results for three samples based on PETG and PETG-CCF printed at $90^{\circ}, 45^{\circ}$, and $45^{\circ} / 45^{\circ}$. In different cases, with and without shells, specimens with a raster orientation of $45^{\circ}-45^{\circ}$ had a lower porosity compared to those at $90^{\circ}$ and $45^{\circ}$. This result confirms that specimens with alternate layups (here $45^{\circ} /-45^{\circ}$ ) had less mass deviation from the mass estimation as compared with specimens printed unidirectionally $\left(45^{\circ}\right.$ and $90^{\circ}$ ). Good filling quality with lower porosity was obtained with alternate layers compared to unidirectional ones, which can be explained by the pore filling thanks to the cross-deposition of raster on the longitudinal voids between the rasters of the previous layer.

\begin{tabular}{|c|c|c|c|}
\hline Raster orientation $\left({ }^{\circ}\right)$ & $\begin{array}{c}\text { Total volume } \\
\qquad\left(\mathrm{mm}^{3}\right)\end{array}$ & $\begin{array}{c}\text { Void volume } \\
\left(\mathrm{mm}^{3}\right)\end{array}$ & Porosity (\%) \\
\hline \multicolumn{4}{|l|}{ With 2 Shells } \\
\hline PETG $90^{\circ}$ & 2602.27 & 149.55 & 5.43 \\
\hline PETG $45^{\circ}$ & 2587.1 & 150.62 & 5.50 \\
\hline PETG $45^{\circ} / 45^{\circ}$ & 2635.94 & 150.68 & 5.41 \\
\hline \multicolumn{4}{|l|}{ Without a shell } \\
\hline PETG $90^{\circ}$ & 2113.93 & 208.71 & 8.99 \\
\hline PETG $45^{\circ}$ & 2225.49 & 244.33 & 9.89 \\
\hline PETG $45^{\circ} / 45^{\circ}$ & 2184.42 & 151.55 & 6.49 \\
\hline \multicolumn{4}{|l|}{ With 2 Shells } \\
\hline PETG - CCF $90^{\circ}$ & 2443.34 & 235.19 & 8.78 \\
\hline $\mathrm{PETG}-\mathrm{CCF} 45^{\circ}$ & 2329.59 & 216.09 & 8.49 \\
\hline PETG - CCF $45^{\circ} /-45^{\circ}$ & 2549.38 & 205.08 & 7.45 \\
\hline \multicolumn{4}{|l|}{ Without a shell } \\
\hline $\mathrm{PETG}-\mathrm{CCF} 90^{\circ}$ & 2401.93 & 202.83 & 7.79 \\
\hline $\mathrm{PETG}-\mathrm{CCF} 45^{\circ}$ & 2622.74 & 157.24 & 5.66 \\
\hline PETG - CCF $45^{\circ} /-45^{\circ}$ & 2367.55 & 152.53 & 6.05 \\
\hline
\end{tabular}

Table 4: Porosity of PETG and PETG-CCF samples printed with and without shells using $\mu \mathrm{CT}$ analysis.

PETG specimens printed without shells had a slightly higher porosity compared to specimens printed with two shells. A possible reason for this is that the manual surface determination did not perfectly limit the surface in the absence of shells with the presence of wider open pores. However, opposite conclusions were found for PETG-CCF specimens, higher porosity was determined in the case of specimens printed with two shells related to the presence of a wide 
void between the shell and the internal filling, which was caused by FFF process as illustrated in pink in Figure 9.a. This defect was only observed on one side of the samples; the other side demonstrated a strong adhesion between the shell and the internal filling.

With two shells, PETG specimens had lower porosity compared to PETG-CCF specimens. The average of porosity was $5 \%$ and $8 \%$, respectively. This result stems from the presence of air inclusions between printed composite filaments. In all printed specimens, the porosity was mostly oriented along the rasters direction as illustrated in some examples presented in Figure 9. This figure shows also a homogenous distribution of pores inside printed samples based PETG and PETG-CCF except for some local porosity distributions presented in red in different examples. The porosity was mostly present along the adjacent printed filaments, which might be due to the poor interlayer adhesion and printing process effects which requires an advanced optimization step of printing parameters. These parameters include nozzle temperature, layers thickness, printing speed, etc. The specimens printed with unidirectional patterns had larger pore sizes compared to specimens with alternate layups. Figure 10 depicts these results in further detail with an example of the distribution of cumulative porosity in function of the void volume for composite samples with two shells printed at $45^{\circ}, 90^{\circ}$, and $45^{\circ} /-45^{\circ}$. At a void volume of $0.5 \mathrm{~mm}^{3}$, the cumulative porosity was at $75 \%, 71 \%$, and $60 \%$ of the total porosity for $45^{\circ}-45^{\circ}, 45^{\circ}$, and $90^{\circ}$, respectively. Larger pores gave rise to higher stress concentrations which resulted in weaker mechanical behavior of specimens with unidirectional layups. This result is then confirmed in tensile tests. The found values of porosity were normal related to $3 \mathrm{D}$ printing process, which was expected due to greater porosity compared to other processes such as injection molding ${ }^{33}$.
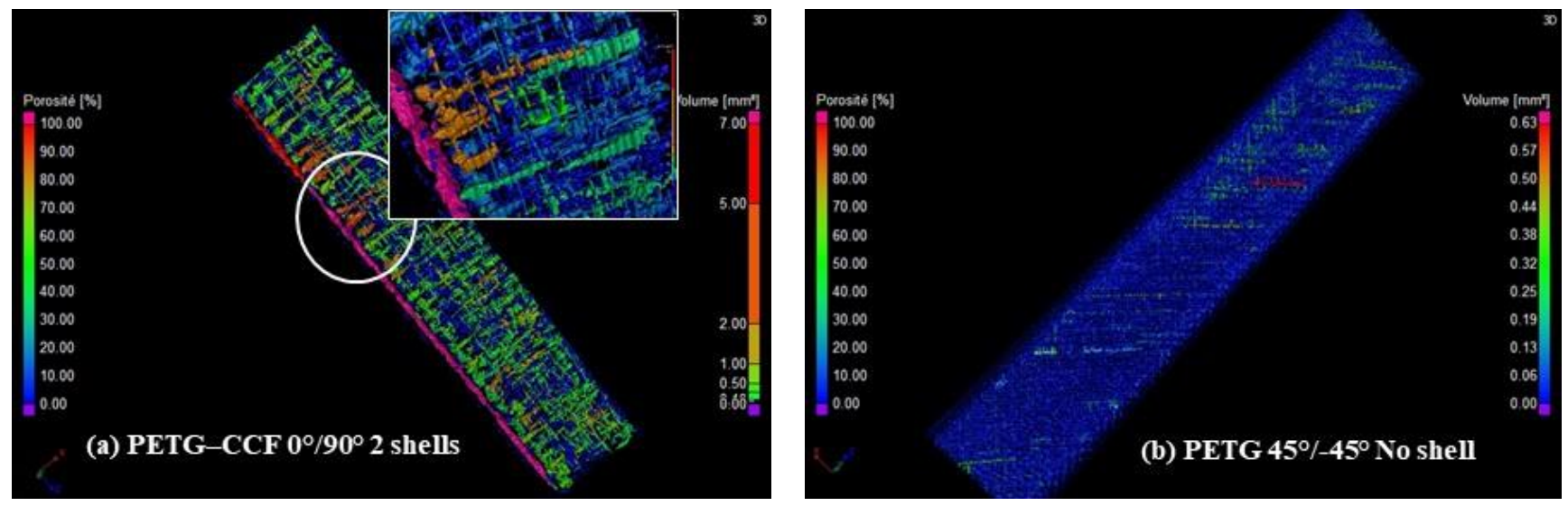

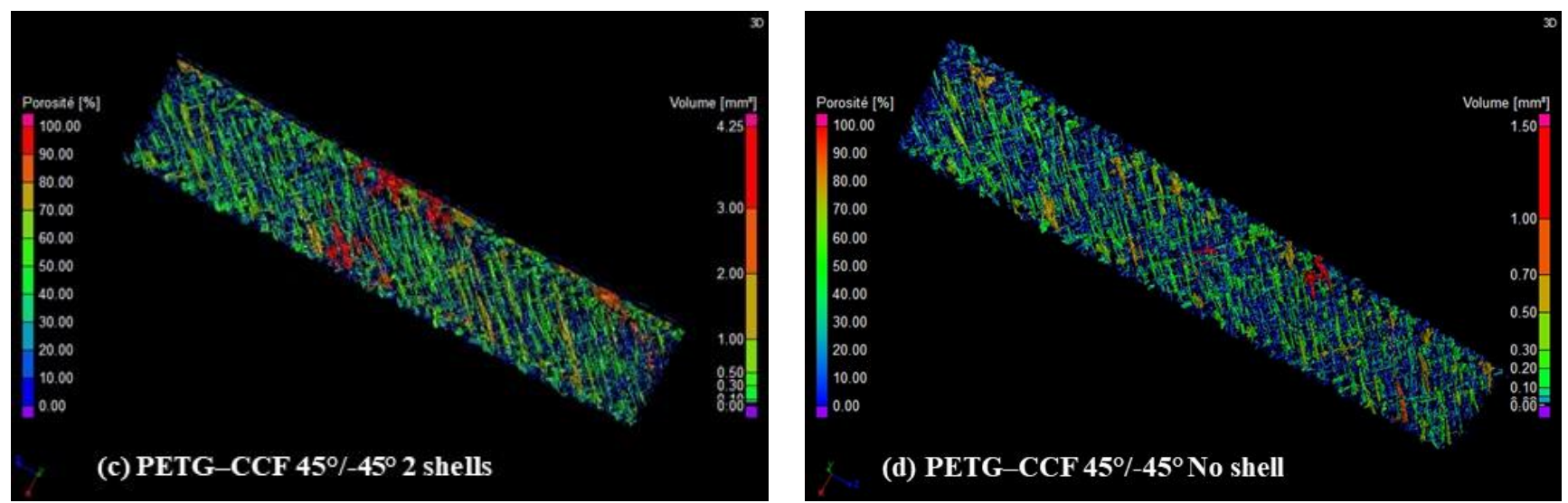

Figure 9: Examples of three dimensional representations of porosity distribution in PETG and PETG-CCF samples with and without shells: (a) PETG - CCF $0^{\circ} / 90^{\circ} 2$ shells, (b) PETG - 45 $\%$ $45^{\circ}$ no shell, (c) PETG - CCF $45^{\circ} /-45^{\circ} 2$ shells, and (d) PETG - CCF 45 $\%-45^{\circ}$ no shell.

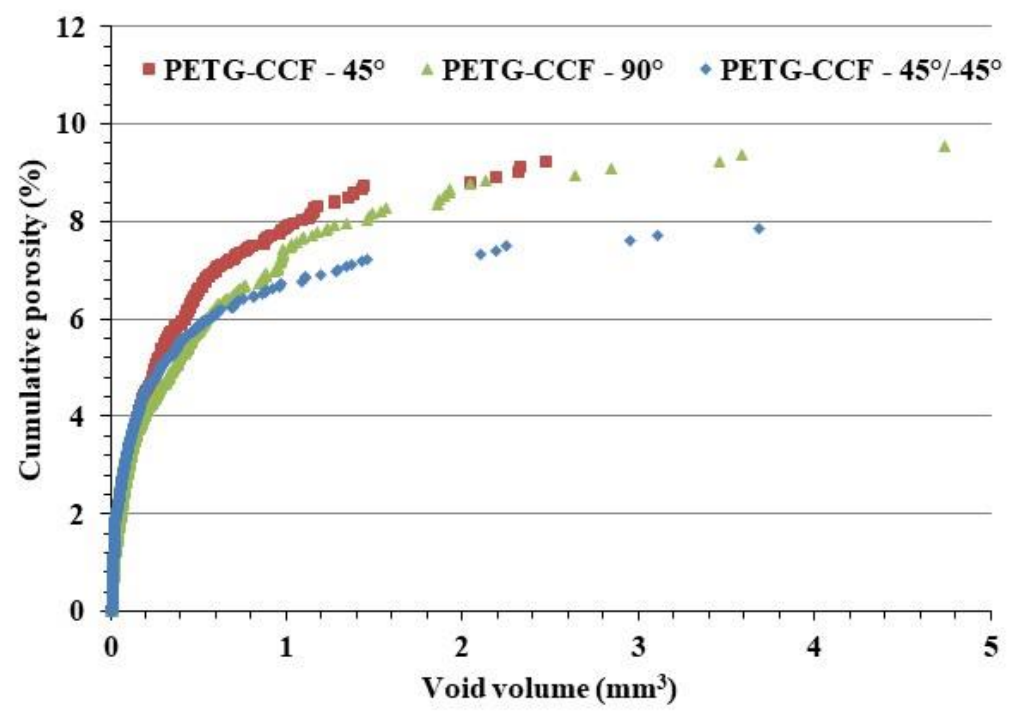

Figure 10: Cumulative porosity distribution for PETG-CCF samples printed at $45^{\circ}, \mathbf{9 0}^{\circ}$, and $45 \%-45^{\circ}$.

\subsection{Tensile test on printed specimens}

The results in this section are presented as follows: first, this section explores the effect of raster orientation on the mechanical performance of PETG specimens printed with two shells and then without a shell. Next, it investigates the effect of CCF composite on the mechanical properties of PETG at different raster orientations, with and without shells.

\subsubsection{Effect of raster orientation on PETG specimens}

For unidirectional layups, Figure 11 summarizes the variation, with error bars, of the mechanical properties including Young's modulus, ultimate tensile strength, and elongation at break of PETG specimens printed with two shells. It was found that the mechanical properties depended on the raster orientation. The highest values of Young's modulus and ultimate tensile 
strength were obtained at $0^{\circ}$ : respectively, $1.47 \mathrm{GPa}$ and $30.7 \mathrm{MPa}$. The ultimate tensile strength decreased gradually with the increase of raster orientation. It ranged from $30.7 \mathrm{MPa}$ at $0^{\circ}$ to 14.1 $\mathrm{MPa}$ at $90^{\circ}$. In addition, a decrease was observed in Young's modulus with the variation of raster orientation from $1.47 \mathrm{GPa}$ at $0^{\circ}$ to $1.05 \mathrm{GPa}$ at $90^{\circ}$. Higher elongation at break of around $2.9 \%$ was obtained at $0^{\circ}$. This decreased to a slightly similar value around $1.1 \%$ for other raster orientations. This orthotropic behavior was similar to that observed by M. Ouhsti et al. when studying PLA specimens ${ }^{34}$.

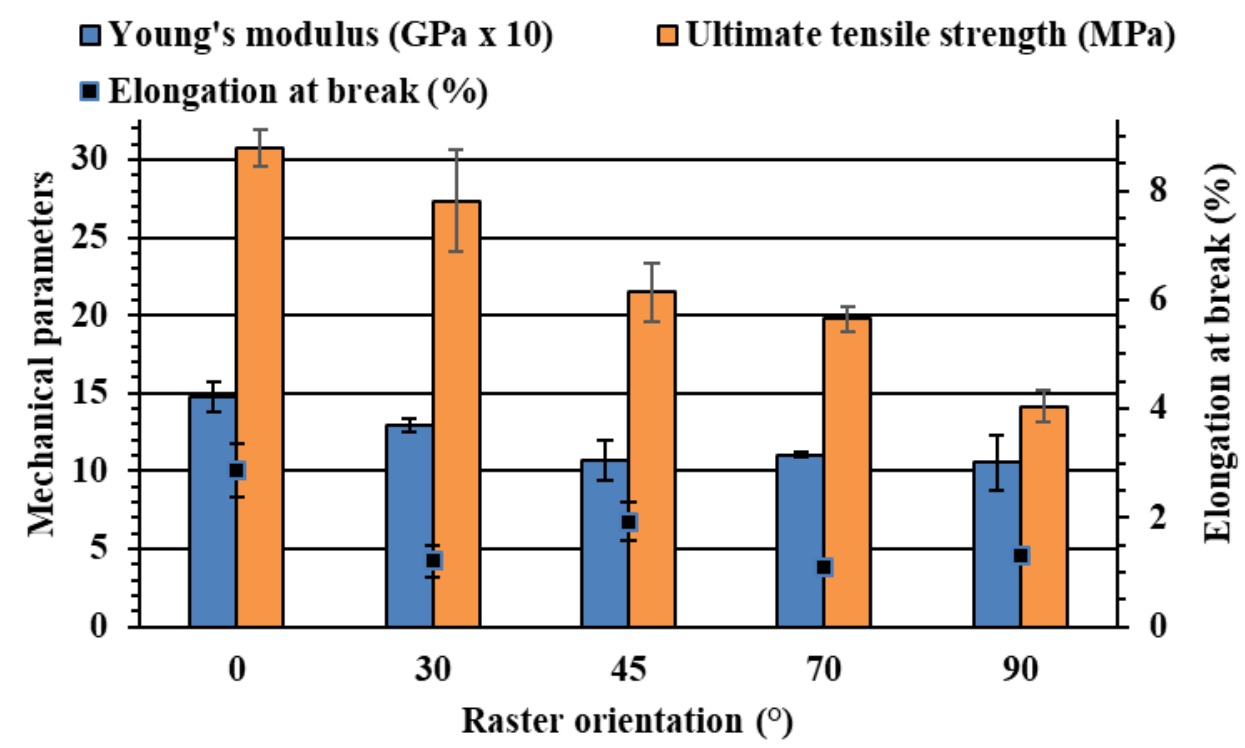

\section{Figure 11: Effect of raster orientation on the mechanical properties of PETG specimens printed with two shells.}

For PETG specimens printed without shells, the highest values of Young's modulus and ultimate tensile strength were also obtained at $0^{\circ}$. They were $1.59 \mathrm{GPa}$ and $31.6 \mathrm{MPa}$, respectively, (Figure 12). The ultimate tensile strength and Young's modulus decreased with the increase of raster orientation. Their lowest values, 5.8 MPa and 0.9 GPa, respectively, were obtained at $45^{\circ}$ and then increased to $8.7 \mathrm{MPa}$ and $1.1 \mathrm{GPa}$, respectively, at $90^{\circ}$. The higher elongation at break around $15 \%$ obtained at $0^{\circ}$ was due to the lower adhesion between layers, which caused a debonding of printed filaments. Consequently, they were fractured separately as presented in Figure 13. At other raster orientations, the elongation at break was at a constant value, approximately $1.7 \%$ (Figure 12).

Compared to the results obtained from PETG samples printed with two shells, Young's modulus and ultimate tensile strength, at a raster orientation of $0^{\circ}$, did not change in the absence of shells because all layers were oriented in the same direction as the shell. However, at other raster orientations, the mechanical properties of printed samples without a shell were lower than 
the printed samples with two shells. This can be explained by the anisotropic behavior of the material that was observed previously wherein the layers oriented at $0^{\circ}$ had higher stiffness. As a result, the shell prepared at $0^{\circ}$ significantly contributed to the mechanical behavior of the specimens at other raster orientations. In the presence of shells, the mechanical properties decreased progressively from $0^{\circ}$ to $90^{\circ}$ as shown in Figure 11 . However, without shells, the mechanical properties were higher at a raster orientation of $0^{\circ}$. They significantly decreased, when the raster orientation increased, to achieve quasi-stable values. Regarding the elongation at break, the fracture of samples printed with shells was clean and all the layers cracked simultaneously. This is indicative of brittle behavior, while the fracture initiated easily between printed layers for samples without a shell. These observations are similar to those found by K.G. Mostafa et al. when studying nylon $12^{35}$. To further investigate the failure mechanism, optical micrographic observations of the top view of the broken cross-section were carried out (Figure 14). Except for the raster orientation of $0^{\circ}$ where the printed filaments were broken, the fracture edge was oriented in the direction of the printed rasters for all other raster orientations. This can be explained by the low adhesion bonding between deposited filaments, which means that the rupture is favoured at this zone having weak rigidity. As a result, samples oriented at $45^{\circ}$ break by shear mode rather than tensile mode. These results were consistent with J. Kiendl et al. study on PLA printed unidirectionally without a shell ${ }^{36}$.

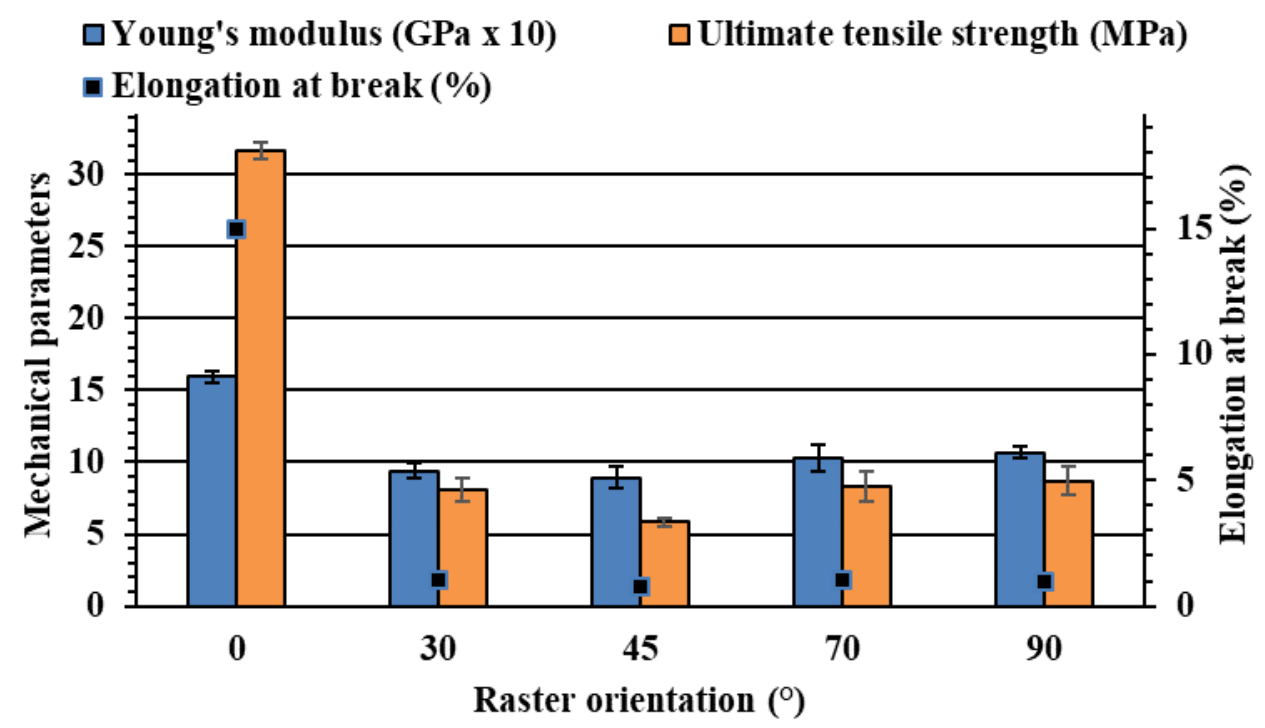

Figure 12: Effect of raster orientation on the mechanical properties of PETG printed without shells. 


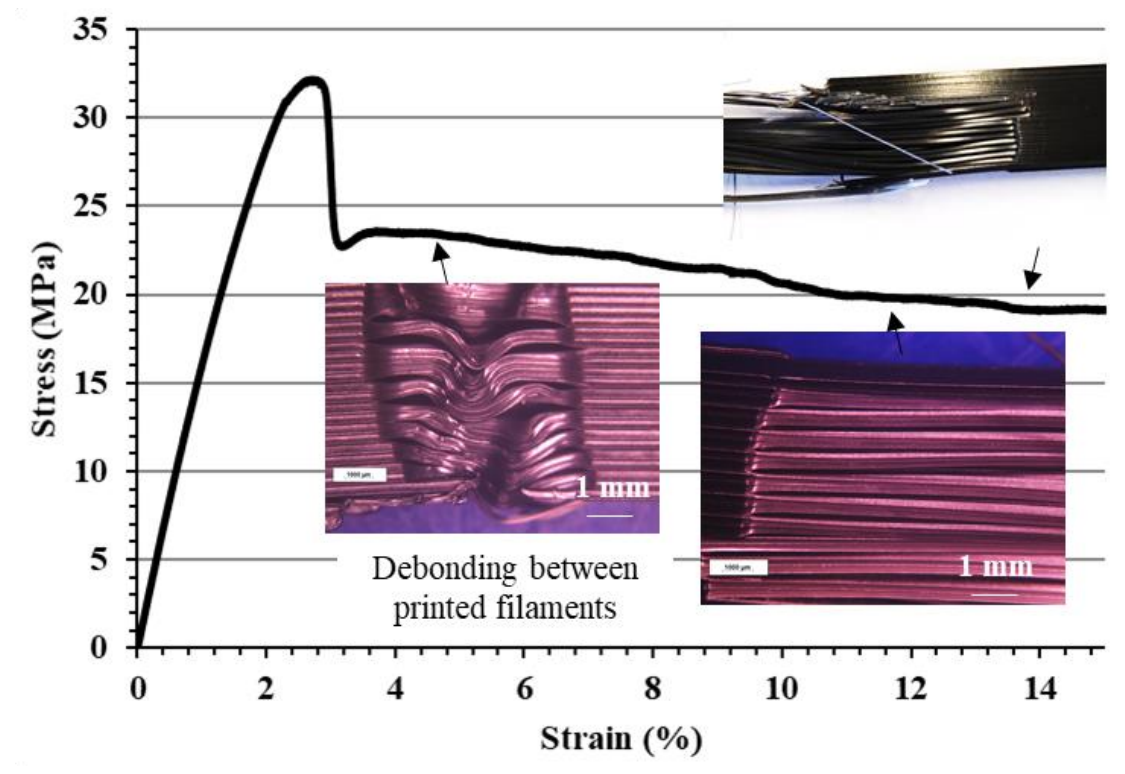

Figure 13: Stress-strain curve of PETG specimens printed without shells at a raster orientation of $0^{\circ}$ showing a debonding of printed filaments.

$30^{\circ}$
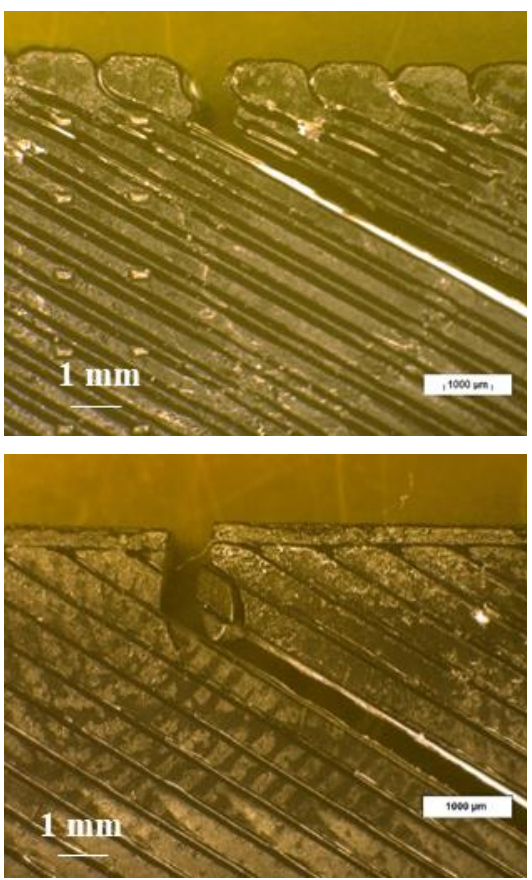

$45^{\circ}$
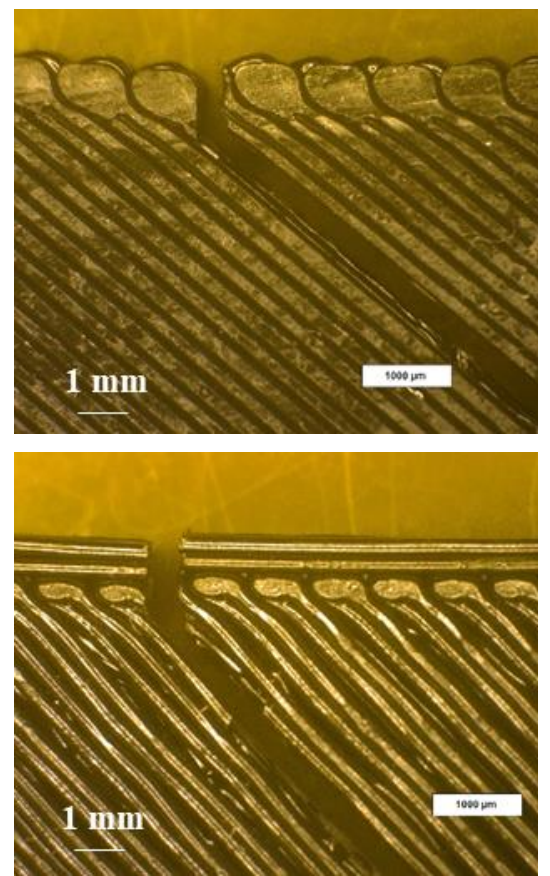

$90^{\circ}$
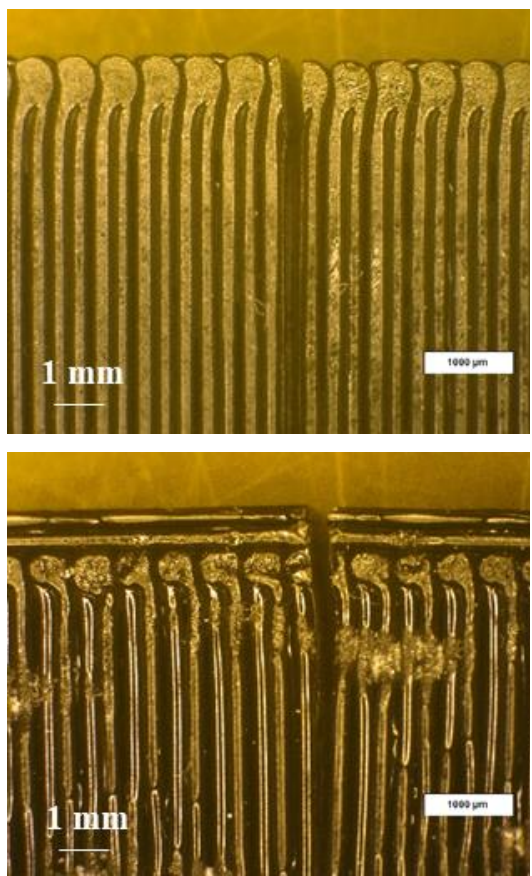

Figure 14: Top view of the fracture in PETG specimens printed at $30^{\circ}, \mathbf{4 5}^{\circ}$, and $90^{\circ}$ without shells (top) and with two shells of PETG (bottom).

In conclusion, the mechanical properties of PETG with layers printed unidirectionally were significantly influenced by the raster orientation and shells presence. Different raster orientations can be combined to create a compensation effect and reduce the influence of raster orientation and shells on the mechanical properties. In addition, the stratification mode for composite materials is generally used, and each layer contributes to the mechanical behavior. The most widely used configuration is a succession of layers oriented at $0^{\circ} / 90^{\circ} / 45^{\circ} / 45^{\circ}$, known 
by its quasi-isotropic properties. For this raison, this study tests two configurations with alternate layers at $0^{\circ} / 90^{\circ}$ and $45^{\circ} / 45^{\circ}$.

Tensile test results performed on PETG samples printed without shells and with two shells at $0^{\circ} / 90^{\circ}$ and $45^{\circ} \%-45^{\circ}$ were presented in Table 5 . Comparing different cases, the presence of shells improved slightly the mechanical properties of PETG samples. The ultimate tensile strength of $0^{\circ} / 90^{\circ}$ samples was around 26.1 MPa without a shell and 27.3 MPa with two shells. In addition, for $45^{\circ} / 45^{\circ}$ samples, the ultimate tensile strength increased slightly from $19.7 \mathrm{MPa}$ to 21.5 MPa after the addition of shells. This increase can be explained by the positive contribution of the rasters oriented at $0^{\circ}$ of the shells. Young's modulus and ultimate tensile strength of specimens with a raster orientation of $0^{\circ} / 90^{\circ}$, with and without shells, were higher than those of specimens with $45^{\circ} / 45^{\circ}$ of raster orientation. It was due to the contribution of layers oriented at $0^{\circ}$. Specimens with $45^{\circ} / 45^{\circ}$ of raster orientation exhibited a ductile behavior with an elongation at break three times higher than the elongation at break of specimens oriented at $0^{\circ} / 90^{\circ}$. The fracture of printed specimens after tensile test experiments are presented in Figure 15. At $0^{\circ} / 90^{\circ}$, the specimens were ruptured at the layer interface. For $45^{\circ} / 45^{\circ}$ specimens, delamination phenomena was observed in layers oriented at $45^{\circ}$. However, layers at $-45^{\circ}$ were fractured at the end of the experiment.

\begin{tabular}{|l|c|c|}
\hline & $\mathbf{0}^{\circ} / \mathbf{9 0}^{\circ}$ & $\mathbf{4 5}^{\circ} / \mathbf{- 4 5}^{\circ}$ \\
\hline \multicolumn{1}{|c|}{ 2 shells of PETG } & & \\
Young's modulus (GPa) & $1.29 \pm 0.02$ & $1.17 \pm 0.03$ \\
Ultimate tensile strength (MPa) & $27.3 \pm 0.3$ & $21.5 \pm 0.6$ \\
Elongation at break (\%) & $5.3 \pm 0.1$ & $14.1 \pm 6.5$ \\
\hline \multicolumn{1}{|c|}{ Without a shell } & & \\
Young's modulus (GPa) & $1.25 \pm 0.05$ & $1.07 \pm 0.08$ \\
Ultimate tensile strength (MPa) & $26.1 \pm 0.9$ & $19.7 \pm 1.1$ \\
Elongation at break (\%) & $4.3 \pm 0.3$ & $21.9 \pm 0.7$ \\
\hline
\end{tabular}

Table 5: Mechanical properties of PETG specimens printed at $0^{\circ} / 90^{\circ}$ and $45^{\circ} /-45^{\circ}$ with and without shells. 

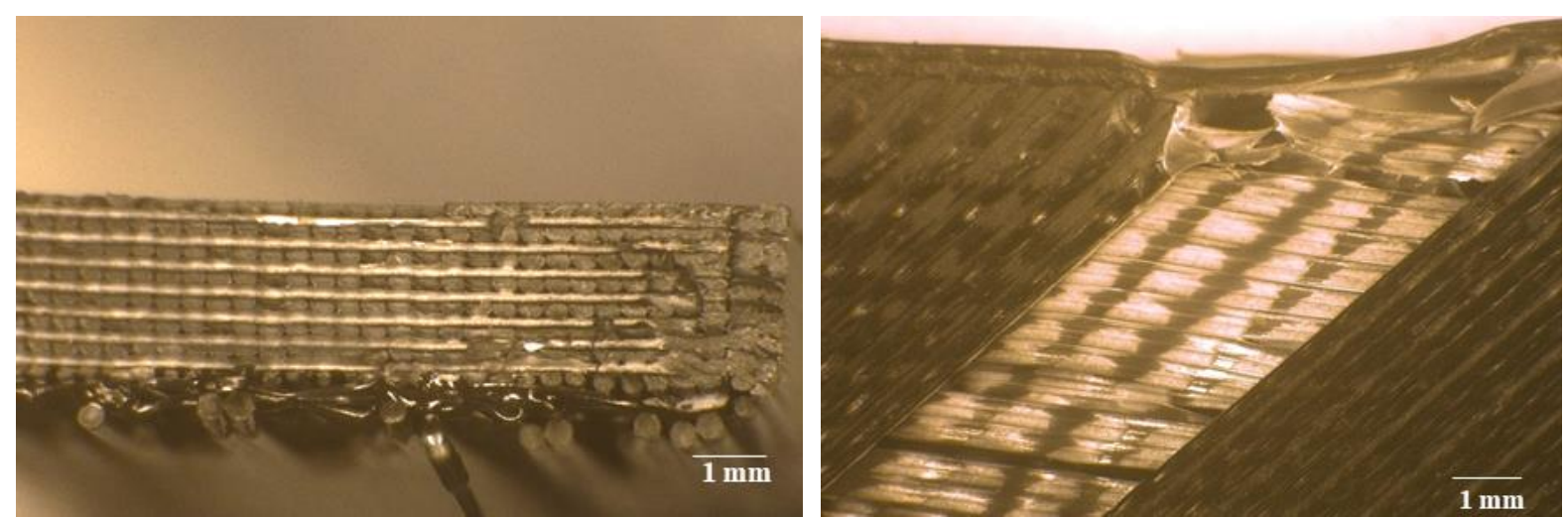

Figure 15: Optical observations of fracture surface of PETG specimens printed with two shells at $0^{\circ} / 90^{\circ}$ (left) and $45^{\circ} /-45^{\circ}$ (right).

\subsubsection{Effect of raster orientation on PETG-CCF specimens}

The effect of raster orientation on the mechanical properties of PETG-CCF specimens printed with two shells are presented in Figure 16. For unidirectional layups, the best mechanical performance occurred at $0^{\circ}$, Young's modulus and ultimate tensile strength of PETG were highly improved by the presence of CCF composite from $1.47 \mathrm{GPa}$ and $30 \mathrm{MPa}$ to $25 \mathrm{GPa}$ (17 times higher) and $268 \mathrm{MPa}$ (9 times higher), respectively. However, the samples became more brittle: the elongation at break was around $1.9 \%$ of PETG-CCF specimens as compared with $2.8 \%$ of PETG specimens. In contrast, at $90^{\circ}$, the addition of CCF composite did not show a major effect on the mechanical properties of PETG. At $45^{\circ}$, PETG-CCF specimens had an intermediate Young's modulus and ultimate tensile strength between $0^{\circ}$ and $90^{\circ}$ : respectively, $2.1 \mathrm{GPa}$ and $18 \mathrm{MPa}$. The same behavior was observed by K. M. M. Billah et al. working on $\mathrm{PC}-\mathrm{CCF}^{37}$. At $0^{\circ}$, fibers were broken sequentially, all layers provided strong tensile resistance. The interface bonding was less solicited in this case and was more solicited at $90^{\circ}$ and $45^{\circ}$. The fracture was propagated along the interface between printed composite filaments due to the lower interlayer adhesion (Figure 17).

Regarding alternate layups, a strong mechanical performance occurred at a raster orientation of $0^{\circ} / 90^{\circ}$ compared to the orientation of $45^{\circ} /-45^{\circ}$. Young's modulus and ultimate tensile strength were, respectively, $11.4 \mathrm{GPa}$ and $155 \mathrm{MPa}$ at $0^{\circ} / 90^{\circ}$. This contrasts with $3.1 \mathrm{GPa}$ and $50 \mathrm{MPa}$ obtained at $45^{\circ} /-45^{\circ}$ due to the presence of composite layers oriented at $0^{\circ}$. The propagation of fracture by delamination and debonding of printed filaments was dominant (Figure 17). This behavior at alternate layups was similar to that observed by F. Ning et al. on ABS-CCF ${ }^{38}$. PETG-CCF printed at $45 \%-45^{\circ}$ had the maximum elongation at break of around $23 \%$ due to the deboning between PETG-CCF layers. Higher elongation at break exceeding 20\% was also obtained by S. Vemuganti et al. using another fiber type ${ }^{39}$. However, all other specimens at 
different raster orientations had lower elongations at break of around $2.5 \%$, showing brittle behavior as illustrated in Figure 16.

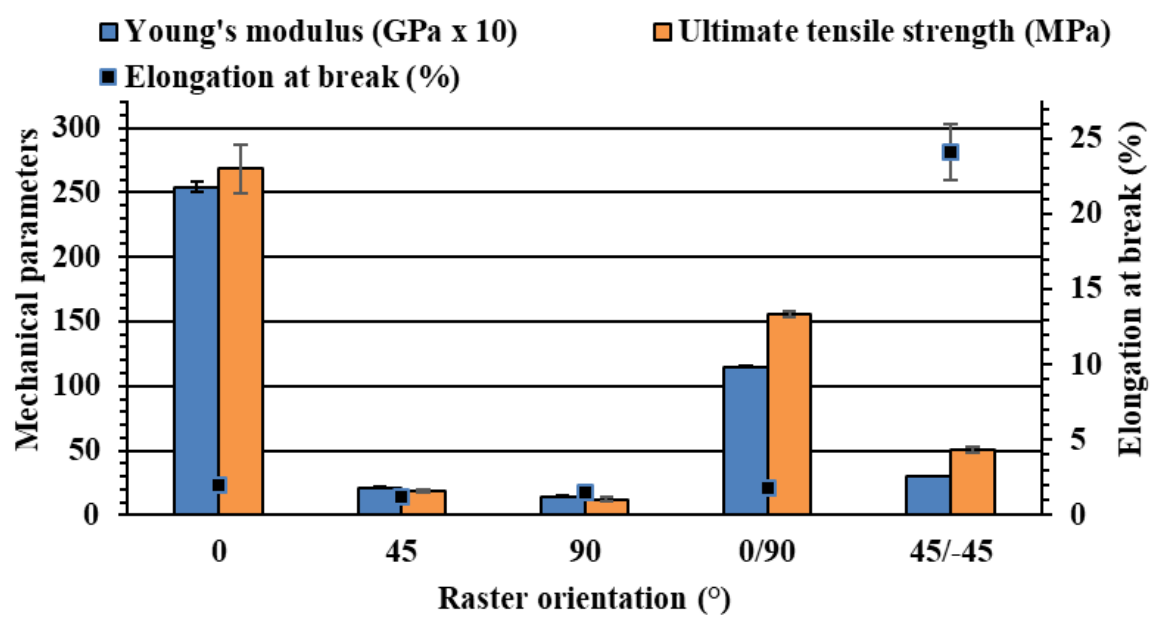

Figure 16: Impact of raster orientation on the mechanical properties of PETG-CCF specimens printed with two shells.

$\mathbf{0}^{\circ}$

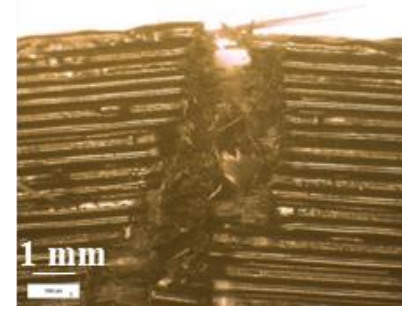

$45^{\circ} /-45^{\circ}$

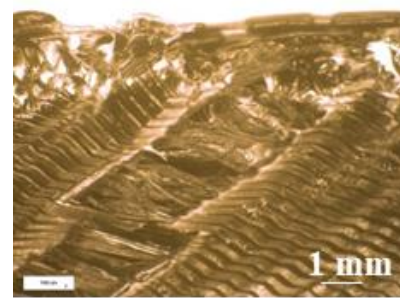

$0^{\circ} / 90^{\circ}$

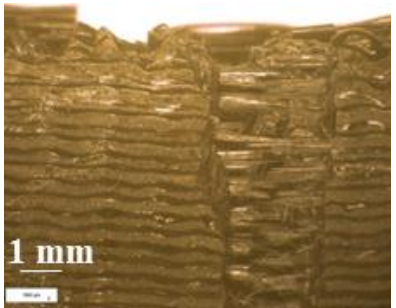

$90^{\circ}$

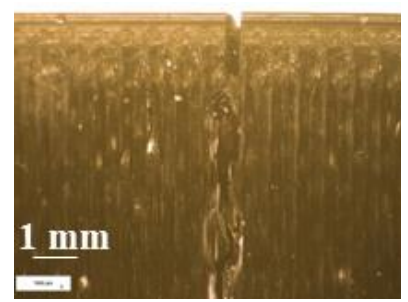

Figure 17: Optical observations of the fracture location in PETG-CCF specimens with two shells printed at different raster orientations $\left(0^{\circ}, 45^{\circ} /-45^{\circ}, 0^{\circ} / 90^{\circ}\right.$, and $\left.90^{\circ}\right)$.

In addition, this study investigates the effect of shells presence contouring the internal filling of specimens. PETG-CCF specimens were printed either with two shells of PETG and without shells. The comparison of their mechanical properties at different raster orientations are depicted in Figure 18.

In the presence of shells, the fraction of fibers in the printed specimens decreased and the fraction of PETG increased compared to specimens printed without shells. Normally, the mechanical properties have a slight decrease in the presence of shells because the mechanical properties of composites mainly depend on the fraction of fibers and their mechanical contribution and especially at a raster orientation of $0^{\circ}$. For this reason, Young's modulus of composite samples printed without shells at a raster orientation of $0^{\circ}$ and $0^{\circ} / 90^{\circ}$ was higher compared to its value for composite with two shells. However, the opposite effect was observed for ultimate tensile strength, it was higher in the presence of shells. The shells delayed the 
fracture propagation by preventing the initiation of facture along the printed filaments due to the ductility of the unreinforced shell.

For other raster orientations $\left(45^{\circ}, 90^{\circ}\right.$, and $\left.45^{\circ} /-45^{\circ}\right)$, a slight decrease of Young's modulus and ultimate tensile strength occurred in the absence of shells. In those configurations, fibers were less solicited and the shell and the interface adhesion significantly contributed to the mechanical properties of composite. Compared to the effect of fibers, the contributions of non-reinforced polymer on the mechanical properties of composite had been neglected in several studies ${ }^{19,20}$. In conclusion, the variation in mechanical properties of PETG-CCF samples first depends on the raster orientation of printed filaments and the presence of fibers. It then depends on the anisotropy of porosity.

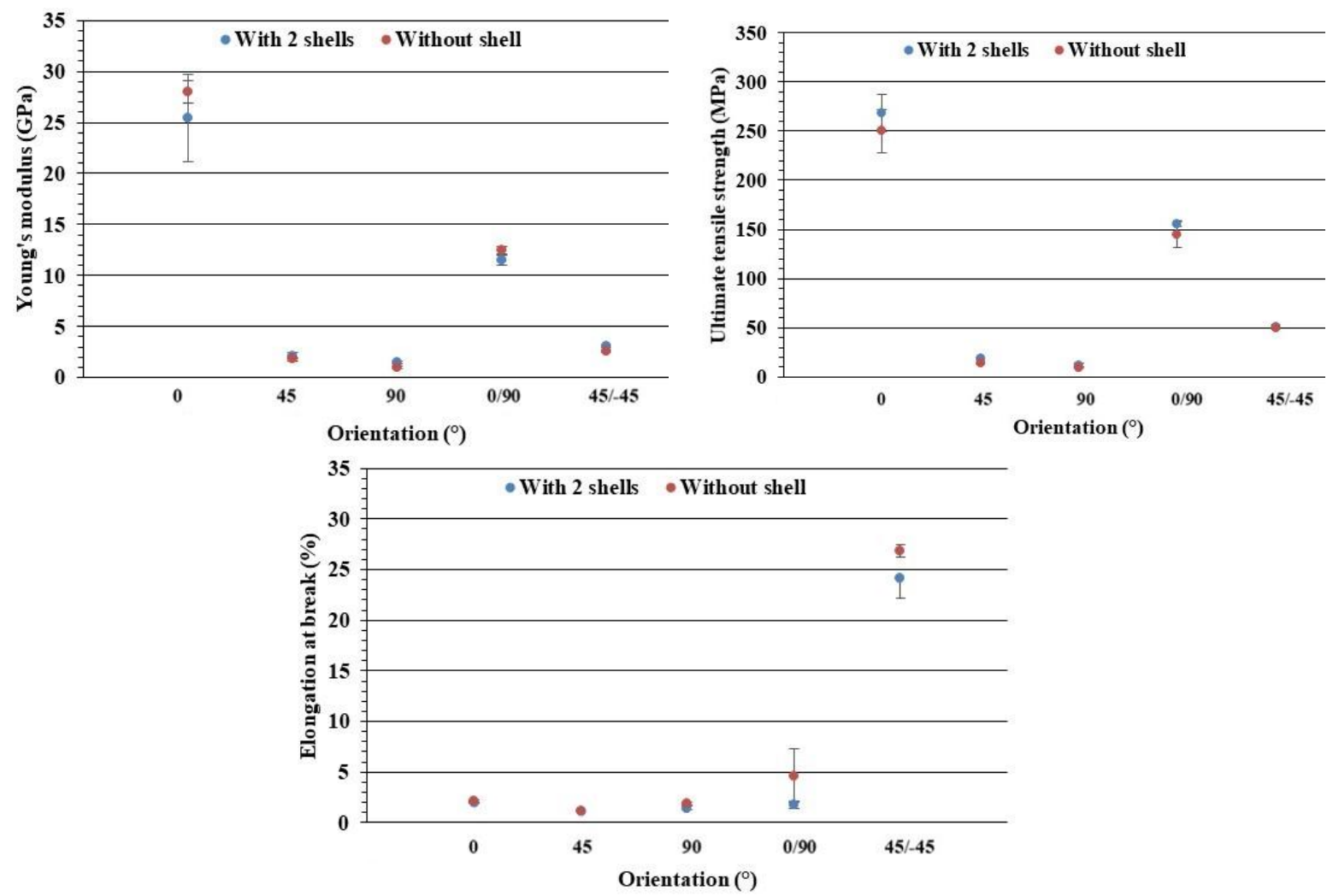

Figure 18: Comparison of the mechanical properties of PETG-CCF printed with and without shells.

\section{Conclusion}

This paper investigates the effect of raster orientation and shells presence on the mechanical properties of PETG and PETG-CCF samples, while assessing the quality of filling of the printed specimens. The matrix polymer presents in CCF composite filament had similar physicochemical properties to those of PETG filament, which shows strong compatibility 
between these two raw materials in FFF. Tomographic observations revealed an anisotropy of the internal porosity in the printed specimens with some local porosity distributions due to weaknesses in the process. It was mostly observed between adjacent printed filaments as a function of raster orientation and between the internal filling and shells. Young's modulus and ultimate tensile strength of PETG and PETG-CCF specimens decreased with the increase in the raster orientation angle. The highest and weakest mechanical properties were obtained, respectively, at $0^{\circ}$ and $90^{\circ}$. Interesting value of elongation at break was obtained at a raster orientation of $45^{\circ} / 45^{\circ}$ of PETG-CCF samples. The presence of shells increased the mechanical strength of PETG specimens. However, Young's modulus of PETG-CCF at a raster orientation of $0^{\circ}$ and $0^{\circ} / 90^{\circ}$ was slightly decreased in the presence of shells due to diminution of fibers fraction. The ultimate tensile strength was increased at those orientations because shells delayed the apparition of fracture. At other raster orientation, the shell and polymer in the internal filling contributed to the mechanical properties because fibers were not solicited in their longitudinal axis. Except for the raster orientation of $0^{\circ}$, the fracture was propagated by shear and delamination phenomena due, at different raster orientations of PETG and PETG-CCF specimens, to the poor interlayer adhesion.

The results show that the properties obtained by 3D printed continuous carbon fiber reinforced composites had higher mechanical properties than non-reinforced thermoplastics. Nevertheless, it remains challenging to improve the mechanical performance of $3 \mathrm{D}$ printed composite by optimising 3D printing process design. Despite, the poor adhesion and anisotropy of porosity, FFF technology has been exponentially gaining attention and popularity as a promising technology for the future development and can lead to the eventual replacement of metal by composite materials in different fields. The results contribute to the mastery of process, design, and composite materials formulation for the optimization of 3D printed high-performance parts. Perspectives include modeling and topology optimization based on the experimental data regarding capability of coextrusion-based 3D printing process and achievable mechanical properties-to-weight ratio.

\section{Acknowledgements}

This project is included in the MATUR Chair, co-financed by the Région Champagne-Ardenne (France) (grant number D201507798), the European Union (grant number D201507799) and UIMM (Partners convention $\left.n^{\circ} 13-2015\right)$. The authors gratefully acknowledge the Chair of 
Biotechnology of CentraleSupélec for their help with the tomographic observations on CCF composite filament.

\section{References}

1. Gibson, I.; Rosen, D.; Stucker, B. Additive Manufacturing Technologies: 3D Printing, Rapid Prototyping, and Direct Digital Manufacturing; Springer.; 2015.

2. Bodaghi, M.; Noroozi, R.; Zolfagharian, A.; Fotouhi, M.; Norouzi, S. Materials 2019, 12, 1353.

3. West, A. P.; Sambu, S. P.; Rosen, D. W. Computer-Aided Design 2001, 33, 65.

4. Ahn, D.; Kweon, J.-H.; Choi, J.; Lee, S. Journal of Materials Processing Technology 2012, $212,339$.

5. $\quad$ Greiner, S.; Wudy, K.; Lanzl, L.; Drummer, D. Polymer Testing 2017, 64, 136.

6. Dudek, P. Archives of Metallurgy and Materials 2013, 58, 1415.

7. El Magri, A.; El Mabrouk, K.; Vaudreuil, S.; Chibane, H.; Touhami, M. E. J Appl Polym Sci 2020, 137, 49087.

8. Ginoux, G.; Vroman, I.; Alix, S. J Appl Polym Sci 2021, 138, 50174.

9. Hwang, S.; Reyes, E. I.; Moon, K.; Rumpf, R. C.; Kim, N. S. Journal of Elec Materi 2015, 44, 771.

10. Nabipour, M.; Akhoundi, B.; Bagheri Saed, A. J Appl Polym Sci 2020, 137, 48717.

11. Wu, Y.; Isakov, D.; Grant, P. Materials 2017, 10, 1218.

12. Liu, W.; Wu, N.; Pochiraju, K. Composites Part A: Applied Science and Manufacturing 2018, $108,1$.

13. Mazzanti, V.; Malagutti, L.; Mollica, F. 2019, 22.

14. Ozkoc, G.; Bayram, G.; Bayramli, E. Polym. Compos. 2005, 26, 745.

15. Sang, L.; Han, S.; Li, Z.; Yang, X.; Hou, W. Composites Part B: Engineering 2019, 164, 629.

16. Shofner, M. L.; Lozano, K.; Rodríguez-Macías, F. J.; Barrera, E. V. J. Appl. Polym. Sci. 2003, 89, 3081.

17. Wolff, E. Introduction to the Dimensional Stability of Composite Materials; DEStech Publications.; 2004.

18. Spoerk, M.; Holzer, C.; Gonzalez-Gutierrez, J. J Appl Polym Sci 2020, 137, 48545.

19. Tian, X.; Liu, T.; Yang, C.; Wang, Q.; Li, D. Composites Part A: Applied Science and Manufacturing 2016, 88, 198.

20. Dong, G.; Tang, Y.; Li, D.; Zhao, Y. F. Procedia Manufacturing 2018, 26, 774.

21. Melenka, G. W. Composite Structures 2016, 10.

22. Dickson, A. N. Additive Manufacturing 2017, 7.

23. Haddou, G.; Dandurand, J.; Dantras, E.; Maiduc, H.; Thai, H.; Giang, N. V.; Trung, T. H.; Ponteins, P.; Lacabanne, C. J Appl Polym Sci 2019, 136, 47623.

24. Caminero, M. A.; Chacón, J. M.; García-Moreno, I.; Rodríguez, G. P. Composites Part B: Engineering 2018, 148, 93.

25. Ding, Q.; Li, X.; Zhang, D.; Zhao, G.; Sun, Z. J Appl Polym Sci 2020, 137, 48786.

26. Yang, C.; Tian, X.; Liu, T.; Cao, Y.; Li, D. Rapid Prototyping Journal 2017, 23, 209.

27. Spoerk, M.; Arbeiter, F.; Cajner, H.; Sapkota, J.; Holzer, C. J. Appl. Polym. Sci. 2017, 134, 45401.

28. Kumar, M. A. Materials Today 2020, 9.

29. Tranchard, P.; Duquesne, S.; Samyn, F.; Estèbe, B.; Bourbigot, S. Journal of Analytical and Applied Pyrolysis 2017, 126, 14.

30. Santana, L.; Alves, J. L.; Sabino Netto, A. da C.; Merlini, C. Matéria 2018, 23, 12267.

31. Brocks, T. Applied Surface Science 2013, 7.

32. Andersons, J.; Joffe, R.; Hojo, M.; Ochiai, S. Part B 2001, 10.

33. Al-Maharma, A. Y. 2020, 28. 
34. Ouhsti, M.; El Haddadi, B.; Belhouideg, S. Mechanics and Mechanical Engineering 2020, 22, 895.

35. Mostafa, K. G.; Montemagno, C.; Qureshi, A. J. Procedia Manufacturing 2018, 26, 753.

36. Kiendl, J.; Gao, C. Composites Part B: Engineering 2020, 180, 107562.

37. Billah, K. M.; Jr, J. L. C.; Chacon, S.; Wicker, R. B.; Espalin, D. 7.

38. Ning, F.; Cong, W.; Hu, Y.; Wang, H. Journal of Composite Materials 2017, 51, 451.

39. Vemuganti, S.; Soliman, E.; Reda Taha, M. Fibers 2020, 8, 53. 